\title{
Regioselective Iodine-catalyzed Construction of Pol- ysubstituted Pyrroles from Allenes and Enamines
}

Yu Wang, Chen-Min Jiang, Hong-Liang Li, Fu-Sheng He, Xiaoyan Luo, and Wei-Ping Deng ${ }^{*}$

School of Pharmacy and Shanghai Key Laboratory of New Drug Design, East China University of Science and Technology, 130 Meilong Road, Shanghai 200237, China

E-mail: xyluo@ecust.edu.cn; weiping_deng@ecust.edu.cn

\section{Table of Contents}

I. ${ }^{1} \mathrm{H}$ NMR and ${ }^{13} \mathrm{C}$ NMR spectra....................................................................S2

II. X-Ray structure of $3 \mathrm{mh}$ and the corresponding data................................S27 


\section{I. ${ }^{1} \mathrm{H}$ NMR and ${ }^{13} \mathrm{C}$ NMR spectra}

${ }^{1}$ H NMR spectrum of compound 3aa
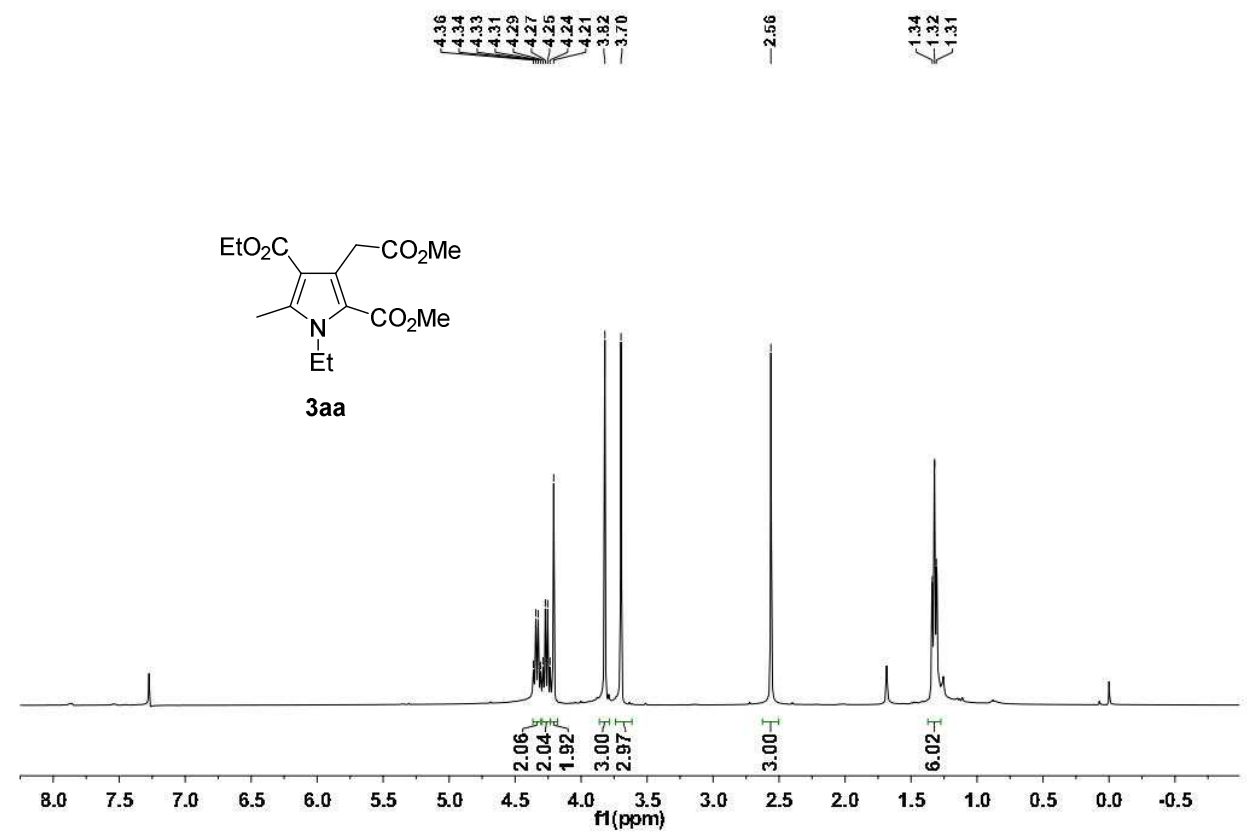

${ }^{13}$ C NMR spectrum of compound 3aa
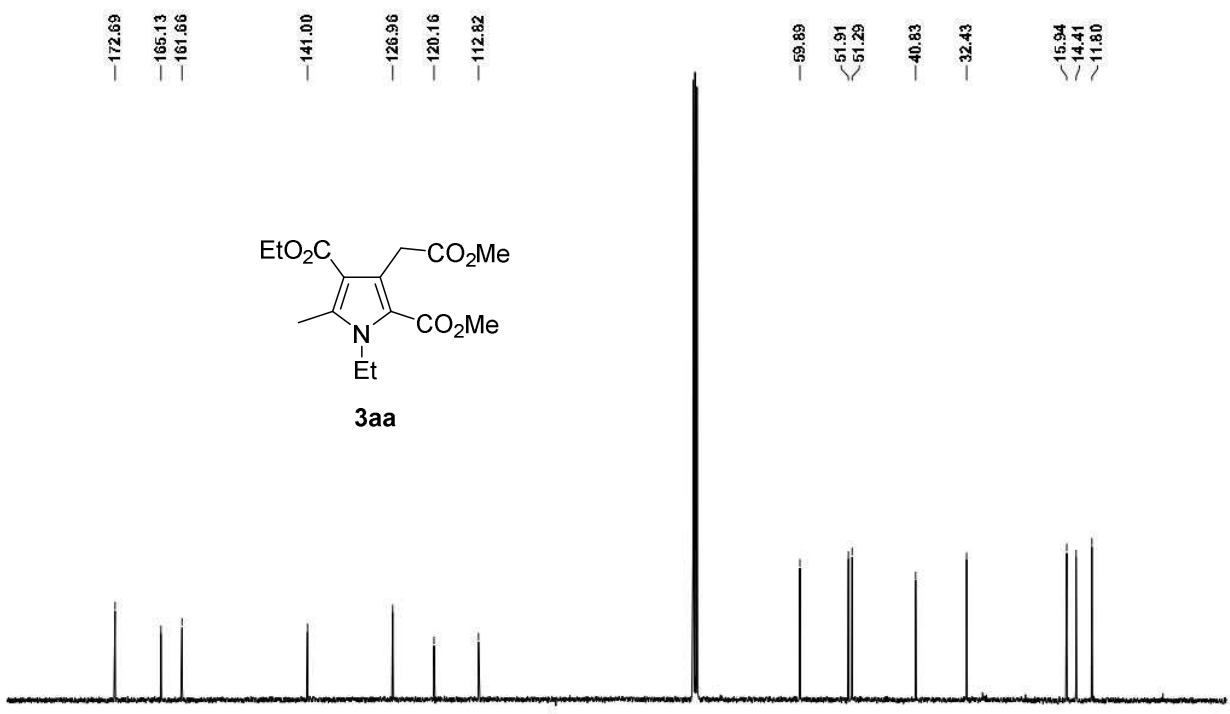

$\begin{array}{lllllllllllllllllllll}190 & 180 & 170 & 160 & 150 & 140 & 130 & 120 & 110 & 100 \begin{array}{c}90 \\ \mathrm{fl}(\mathrm{ppm})\end{array} & 80 & 70 & 60 & 50 & 40 & 30 & 20 & 10 & 0 & -10\end{array}$ 
${ }^{1}$ H NMR spectrum of compound $3 \mathrm{ba}$
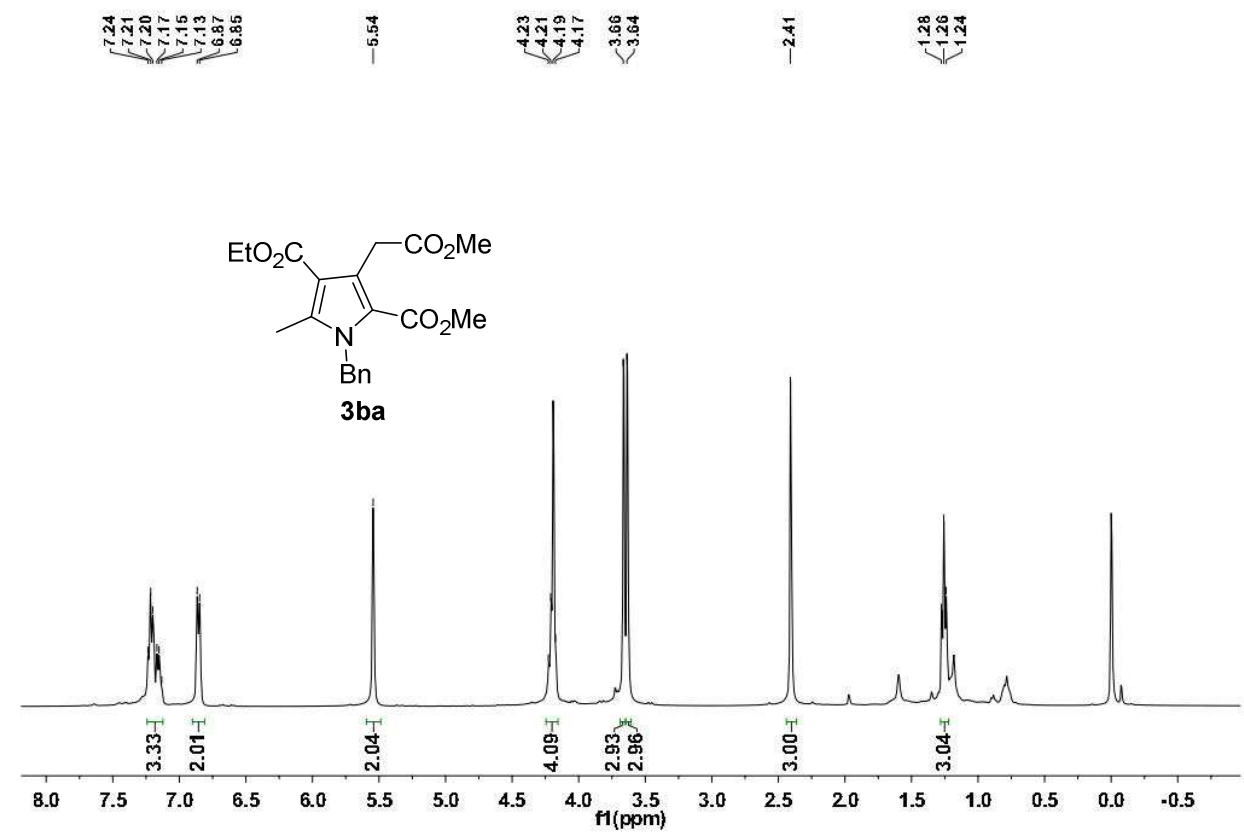

${ }^{13} \mathrm{C}$ NMR spectrum of compound $3 \mathrm{ba}$
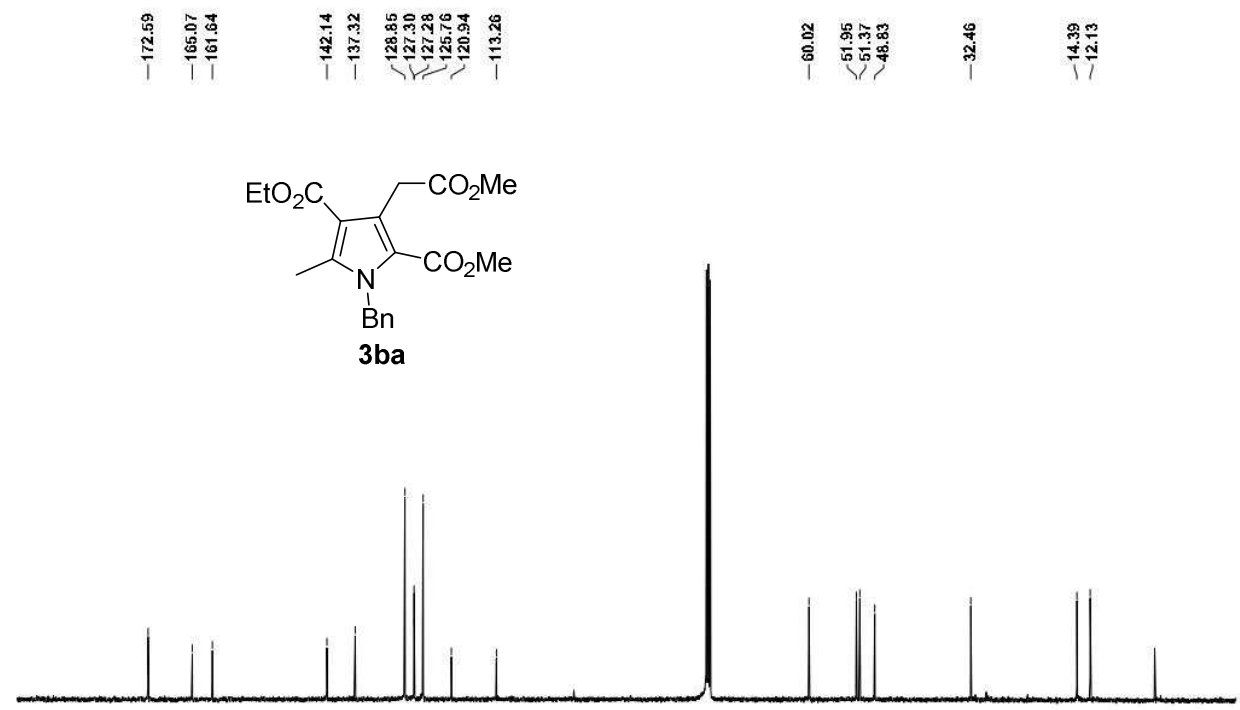

$\begin{array}{lllllllllllllllllllll}190 & 180 & 170 & 160 & 150 & 140 & 130 & 120 & 110 & 100 & \begin{array}{c}90 \\ \mathrm{fl}(\mathrm{ppm})\end{array} & 80 & 70 & 60 & 50 & 40 & 30 & 20 & 10 & 0 & -10\end{array}$ 
${ }^{1}$ H NMR spectrum of compound 3ca
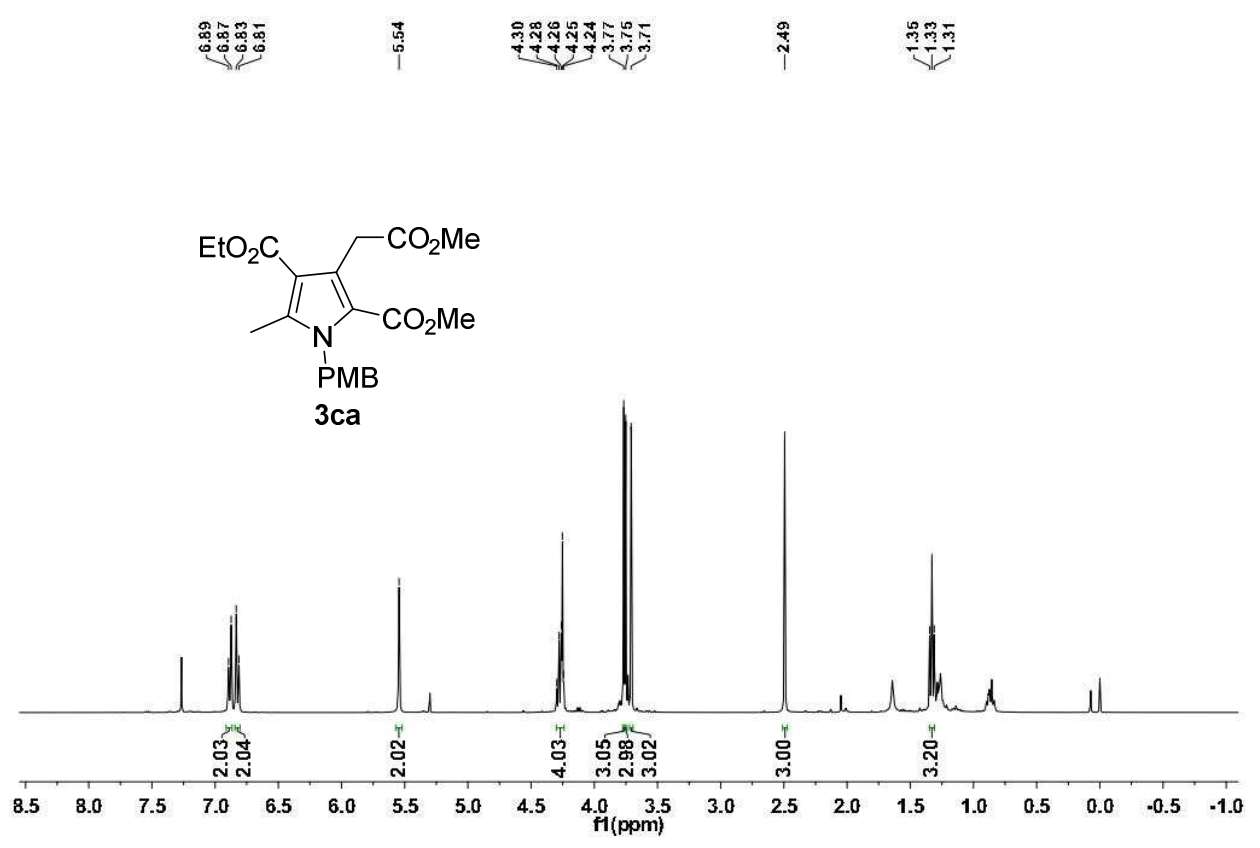

${ }^{13} \mathrm{C}$ NMR spectrum of compound $3 \mathrm{ca}$
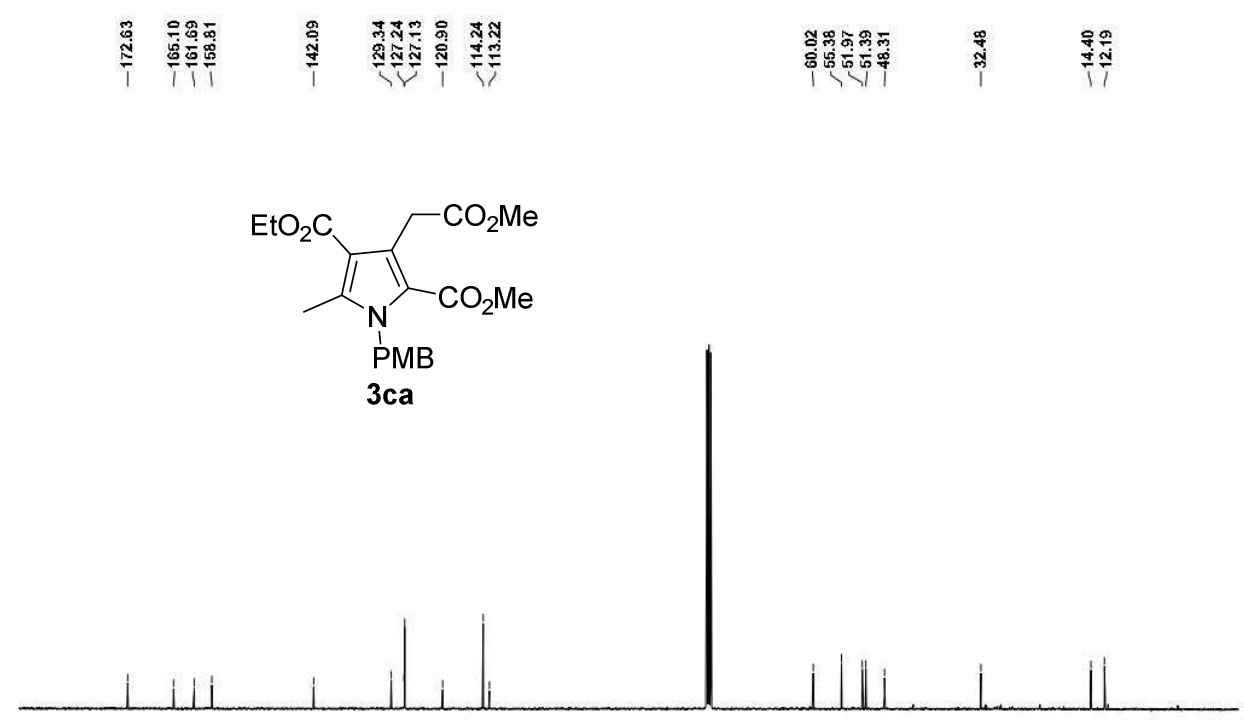

$\begin{array}{rlllllllllllllllllll}190 & 180 & 170 & 160 & 150 & 140 & 130 & 120 & 110 & 100 & \begin{array}{c}90 \\ \mathrm{fl}(\mathrm{ppm})\end{array} & 80 & 70 & 60 & 50 & 40 & 30 & 20 & 10 & 0\end{array}$ 
${ }^{1}$ H NMR spectrum of compound 3da

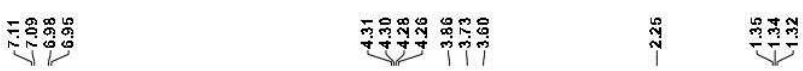

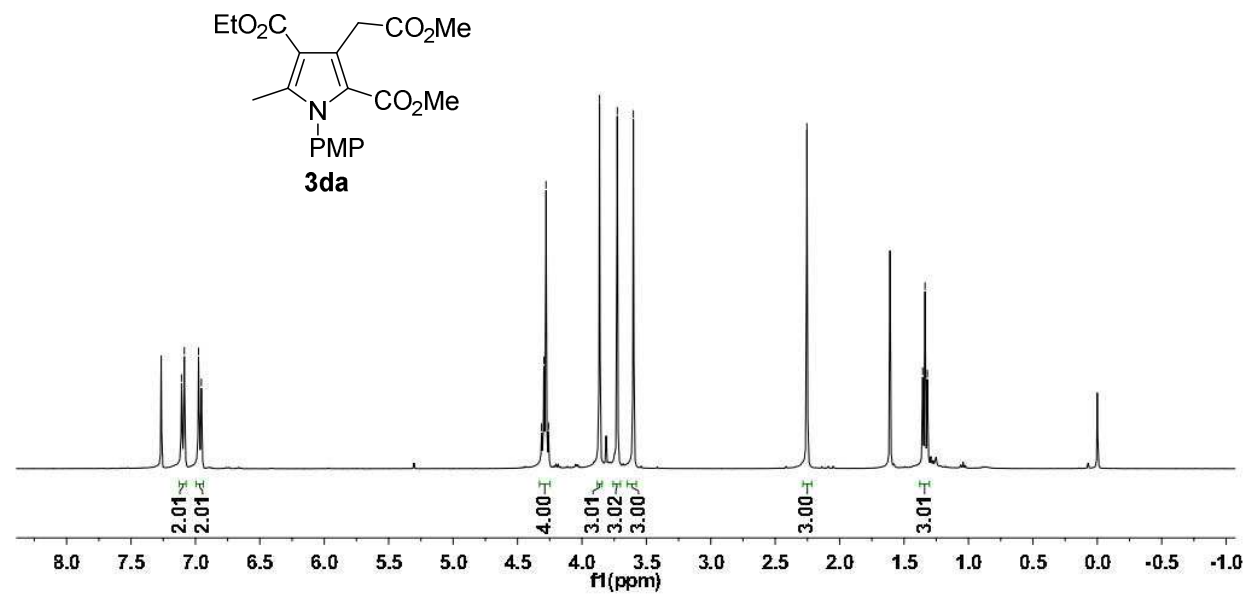

${ }^{13} \mathrm{C}$ NMR spectrum of compound $3 \mathrm{da}$

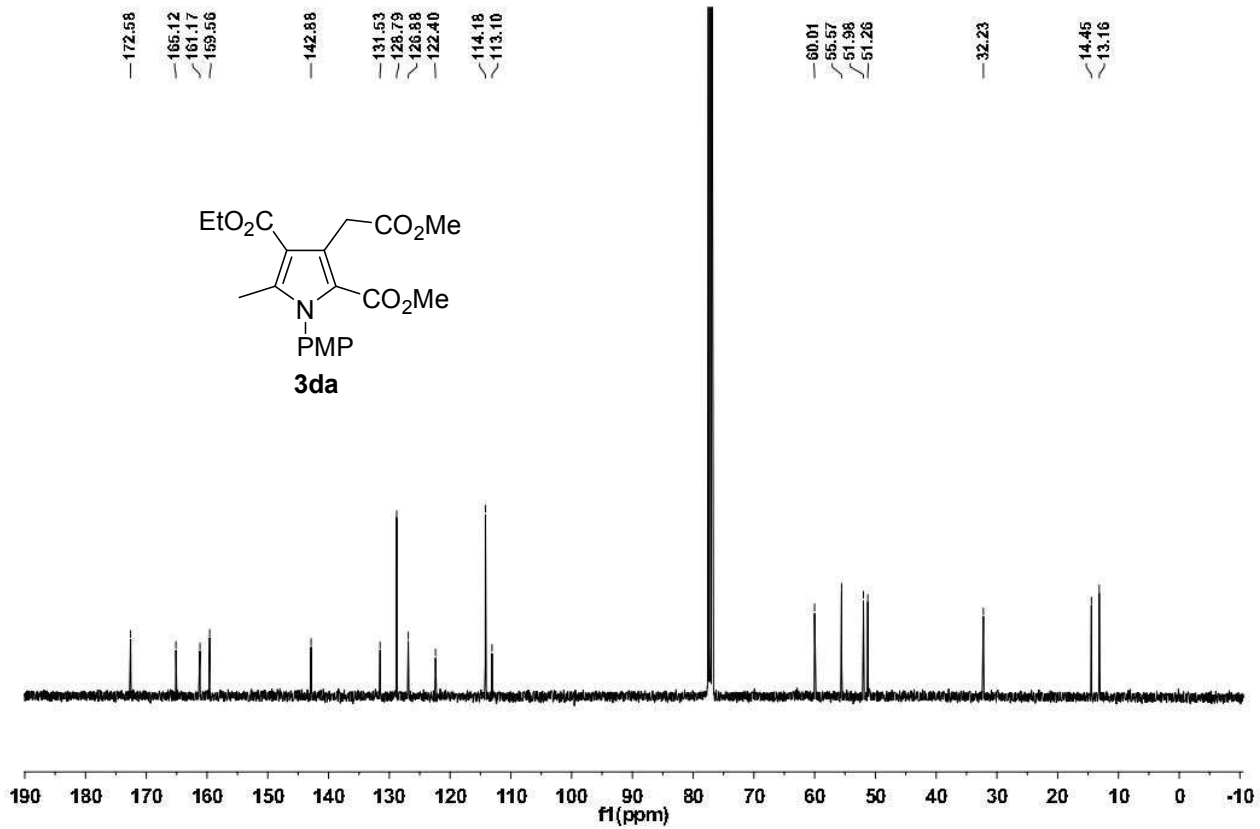


${ }^{1}$ H NMR spectrum of compound 3ea
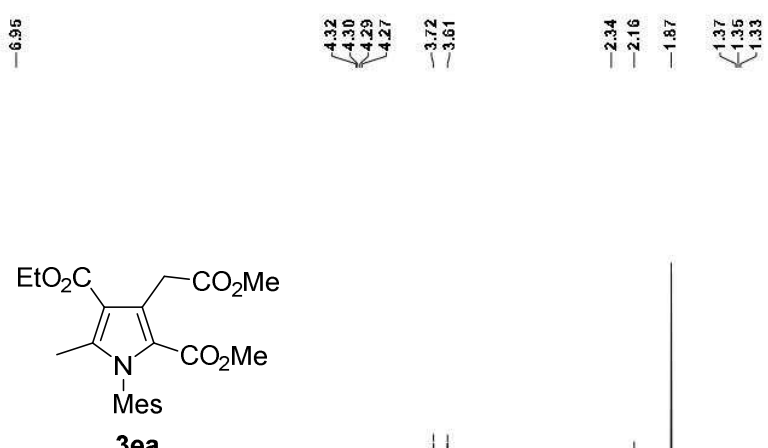

3ea

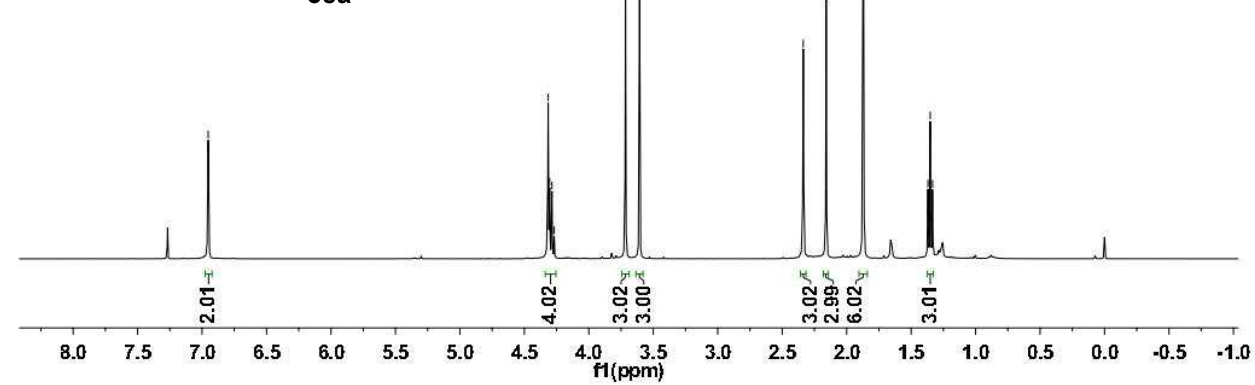

${ }^{13} \mathrm{C}$ NMR spectrum of compound 3ea
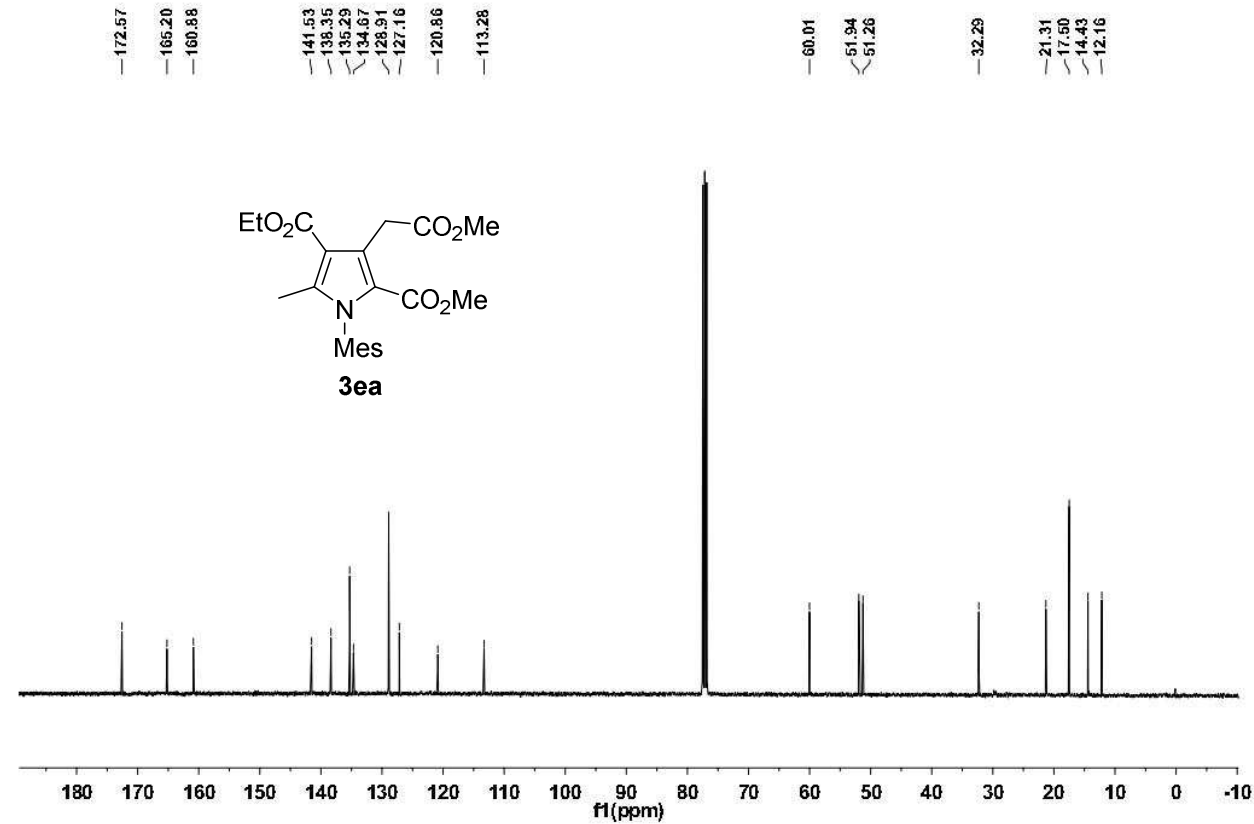
${ }^{1}$ H NMR spectrum of compound 3 fa
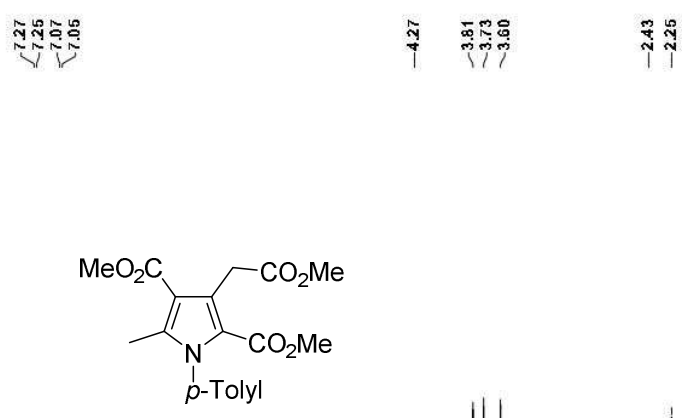

$3 f a$

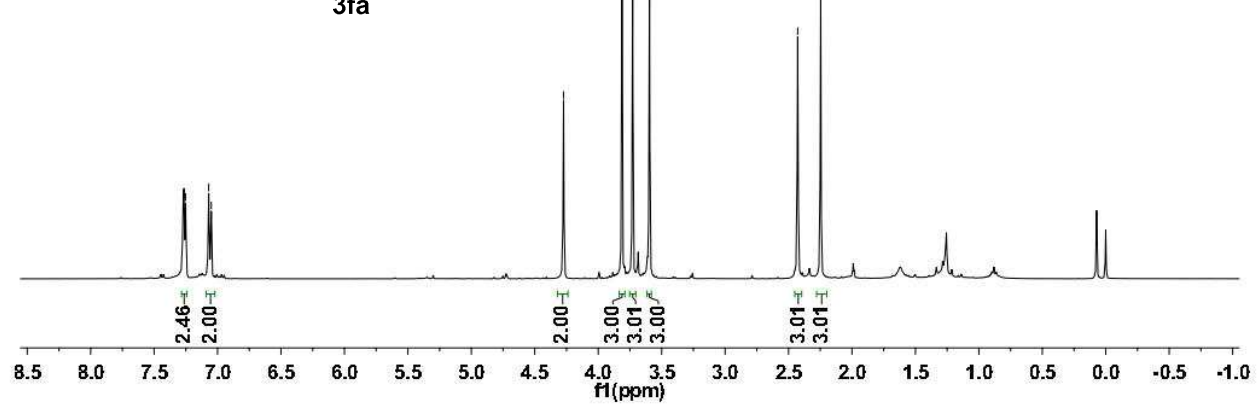

${ }^{13} \mathrm{C}$ NMR spectrum of compound $3 \mathrm{fa}$

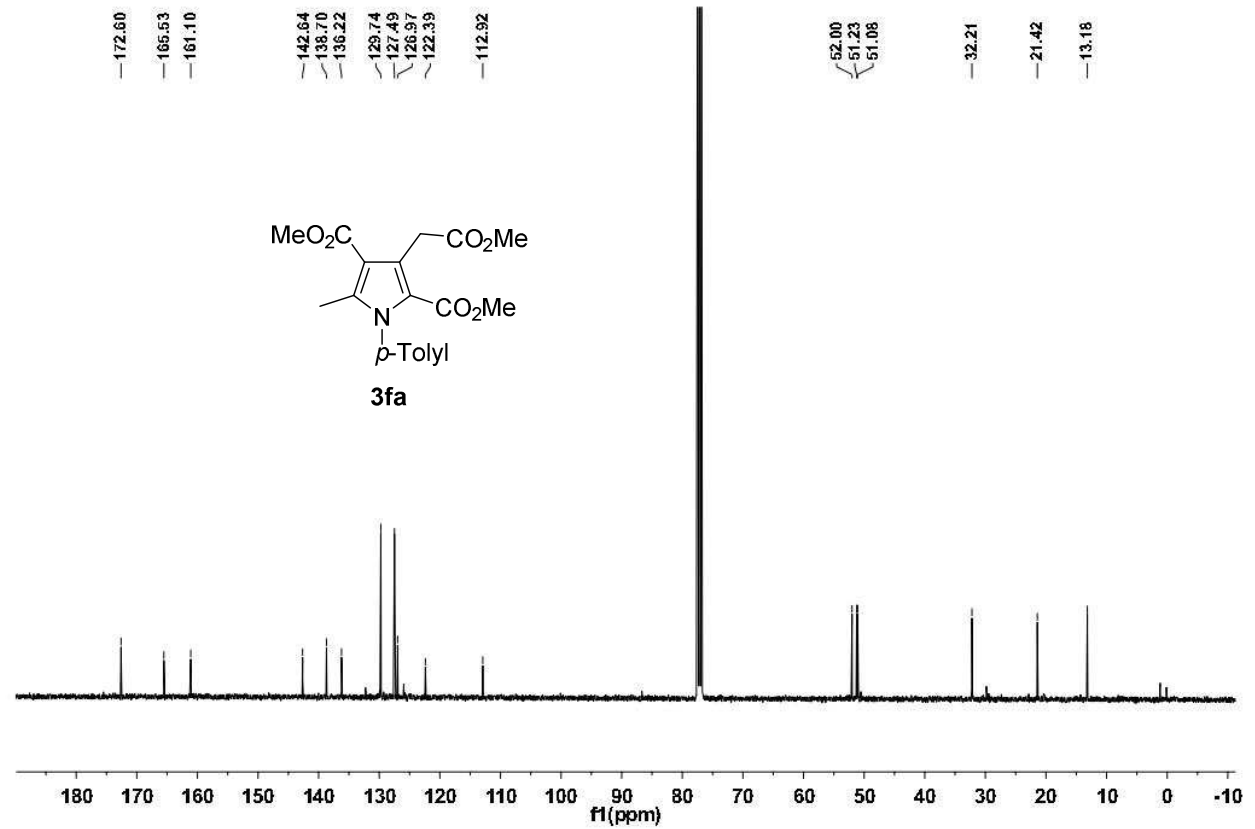


${ }^{1}$ H NMR spectrum of compound 3ga

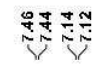

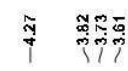
ฟี
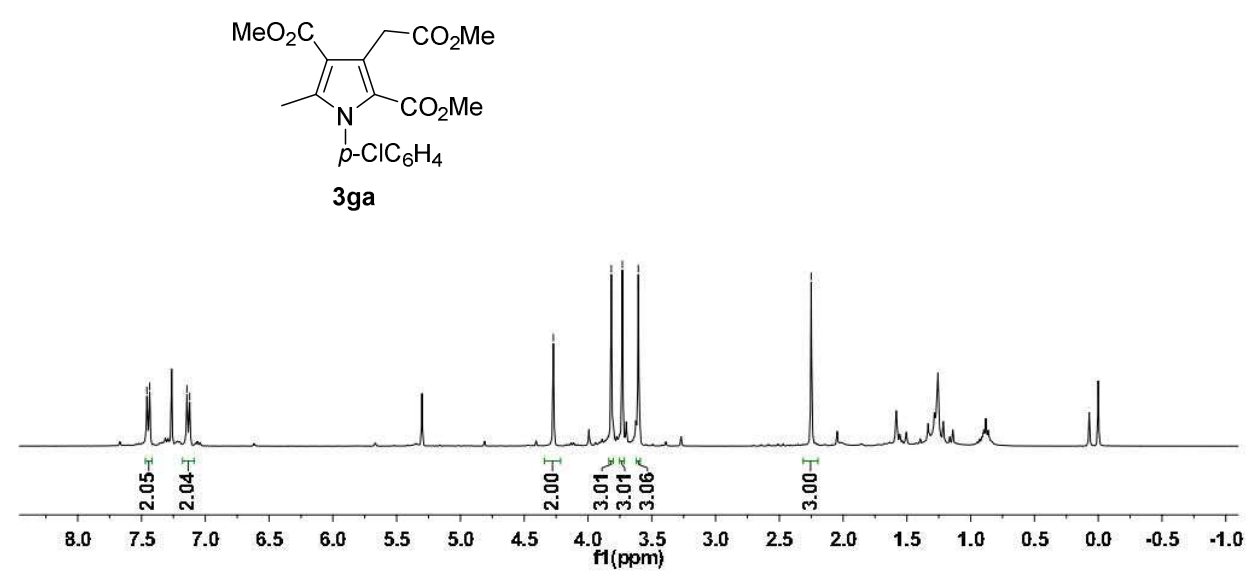

${ }^{13} \mathrm{C}$ NMR spectrum of compound 3ga

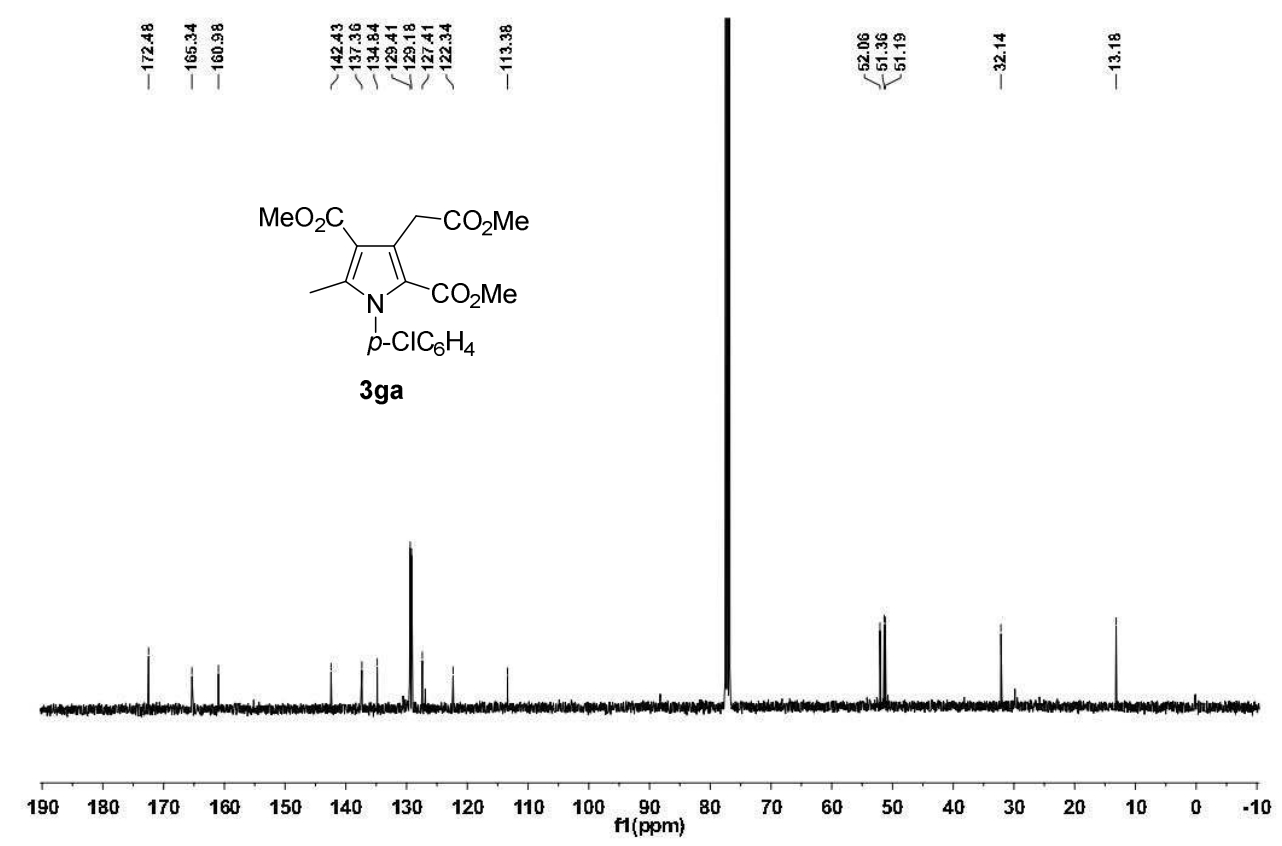


${ }^{1}$ H NMR spectrum of compound 3ha
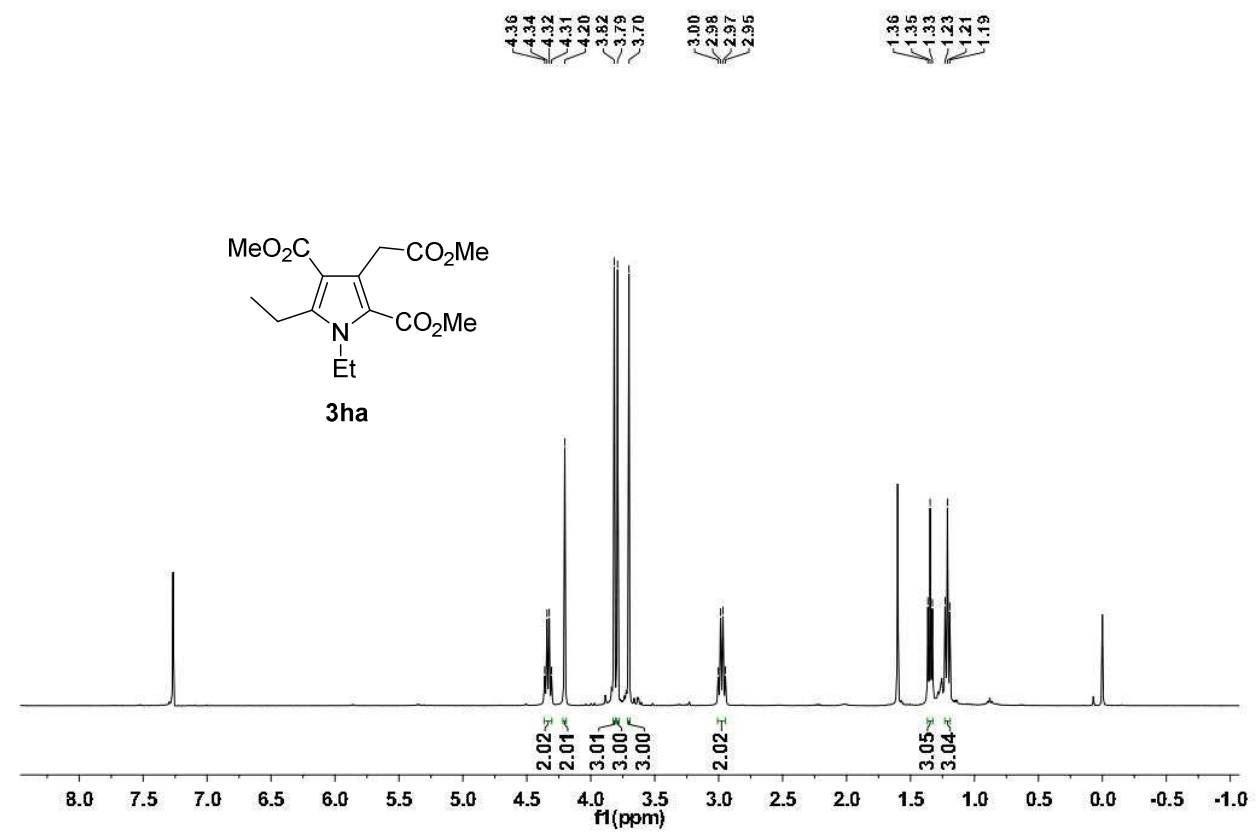

${ }^{13} \mathrm{C}$ NMR spectrum of compound $3 \mathrm{ha}$

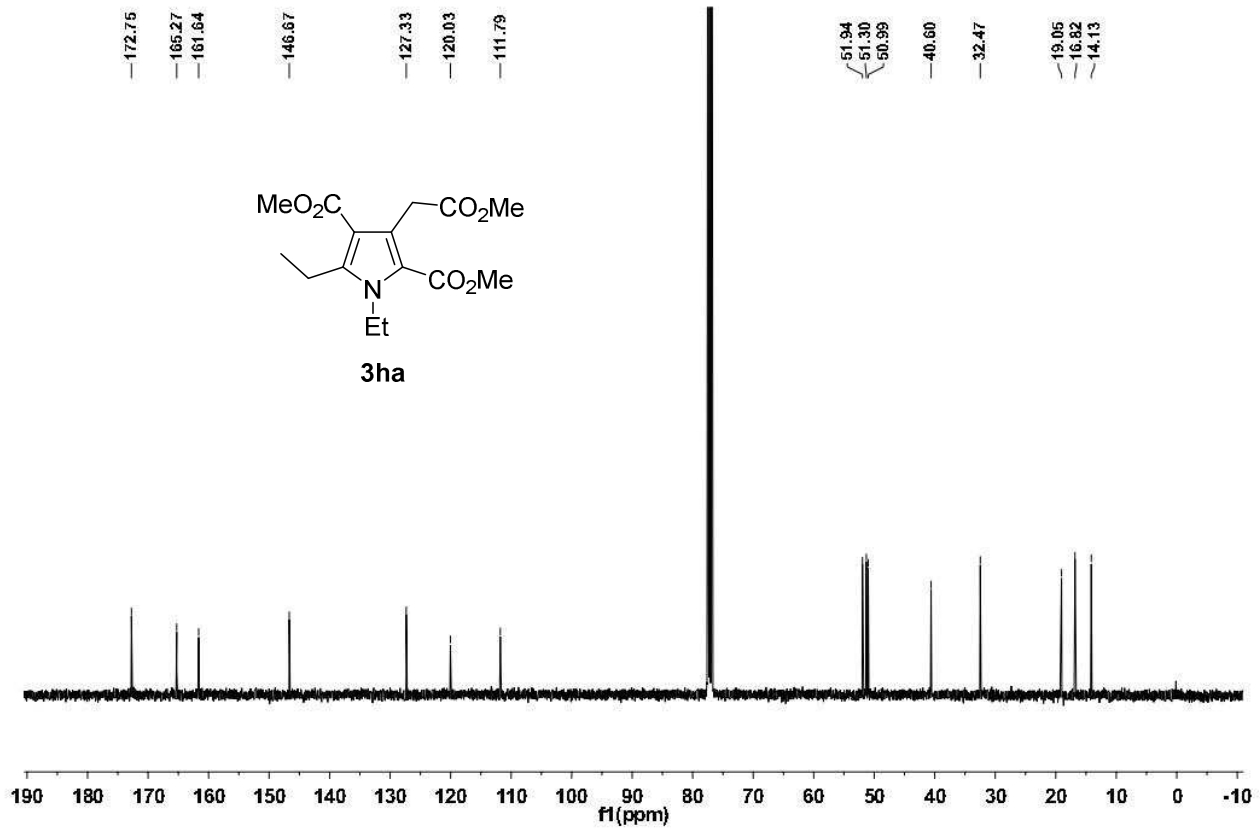


${ }^{1}$ H NMR spectrum of compound 3ia
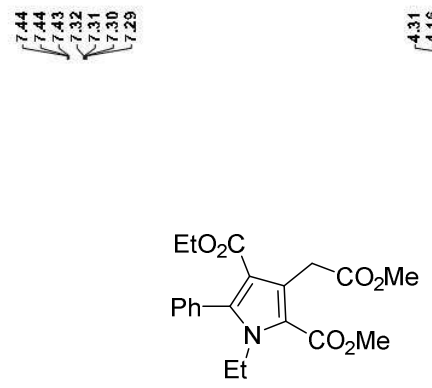

3ia

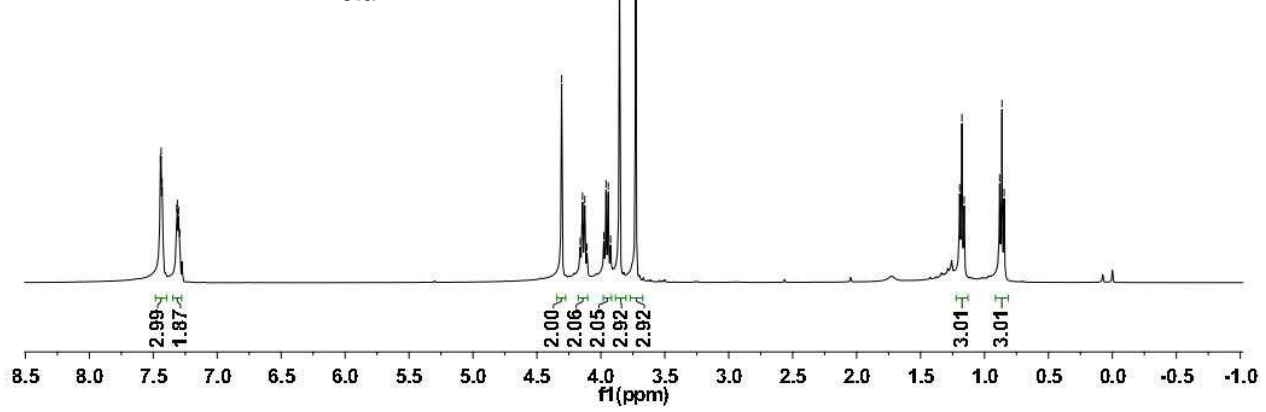

${ }^{13} \mathrm{C}$ NMR spectrum of compound 3ia
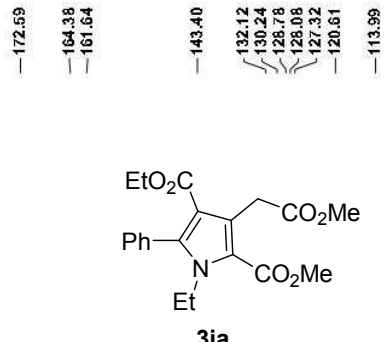

3ia
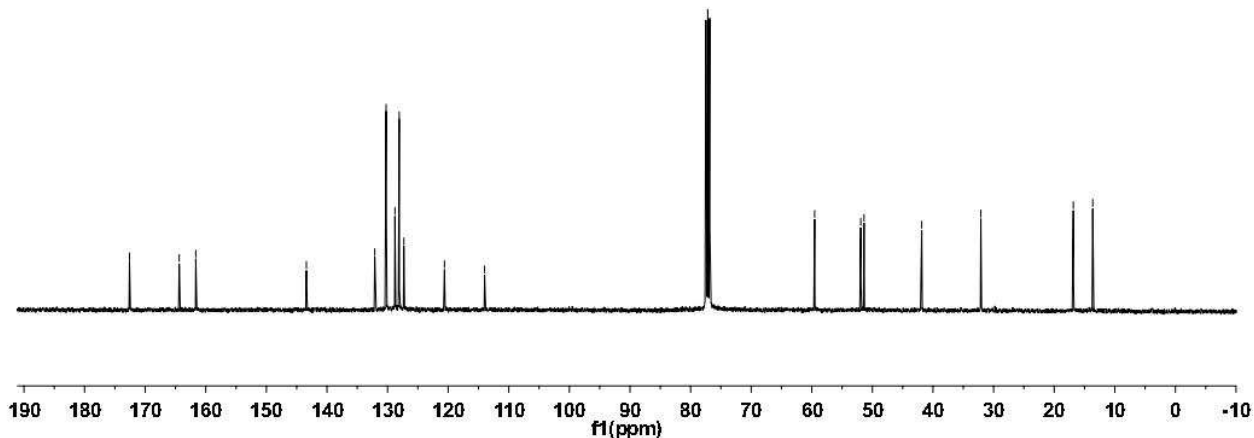
${ }^{1}$ H NMR spectrum of compound $3 \mathbf{j a}$

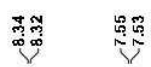

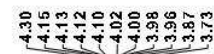

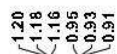
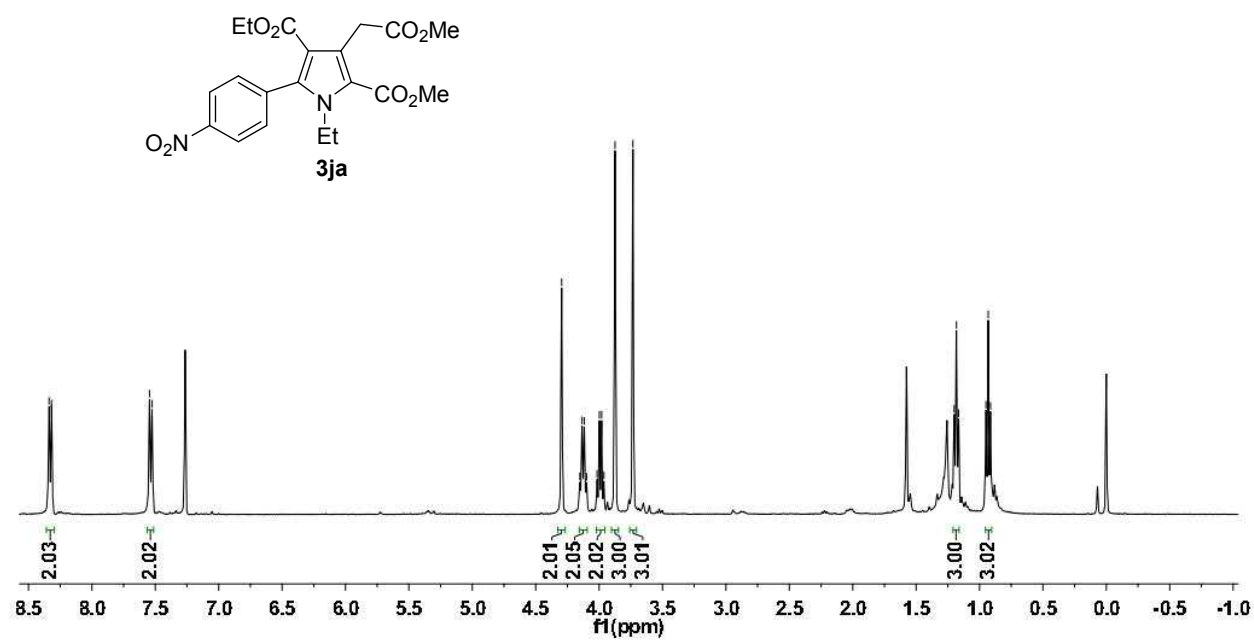

${ }^{13} \mathrm{C}$ NMR spectrum of compound $3 \mathrm{ja}$

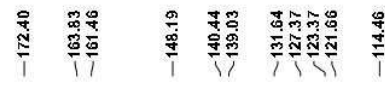

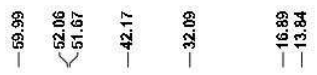
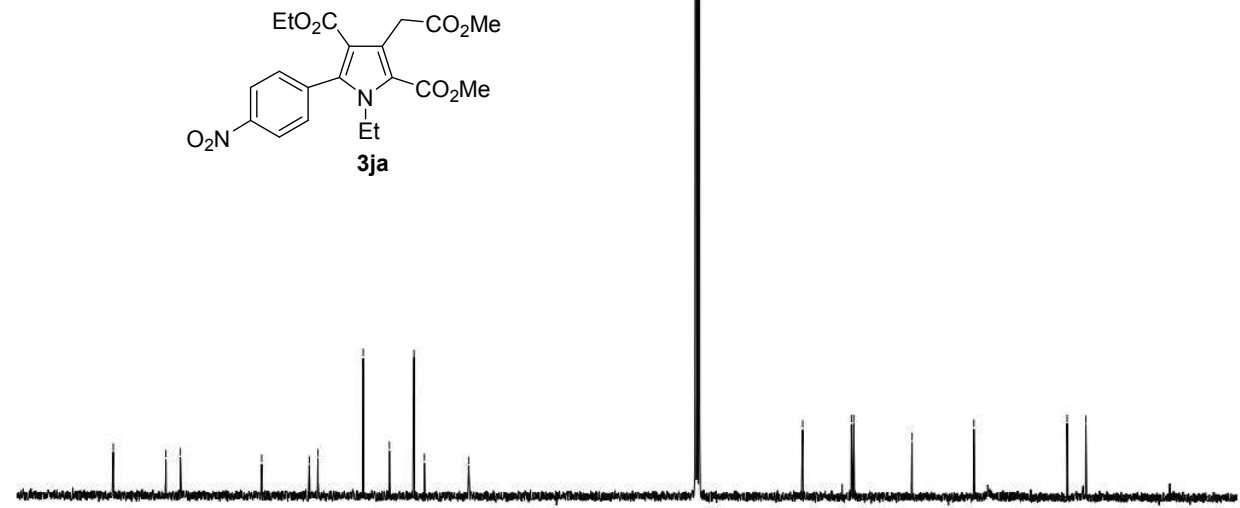

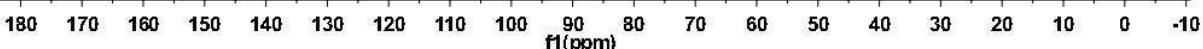


${ }^{1} \mathrm{H}$ NMR spectrum of compound $3 \mathrm{ka}$

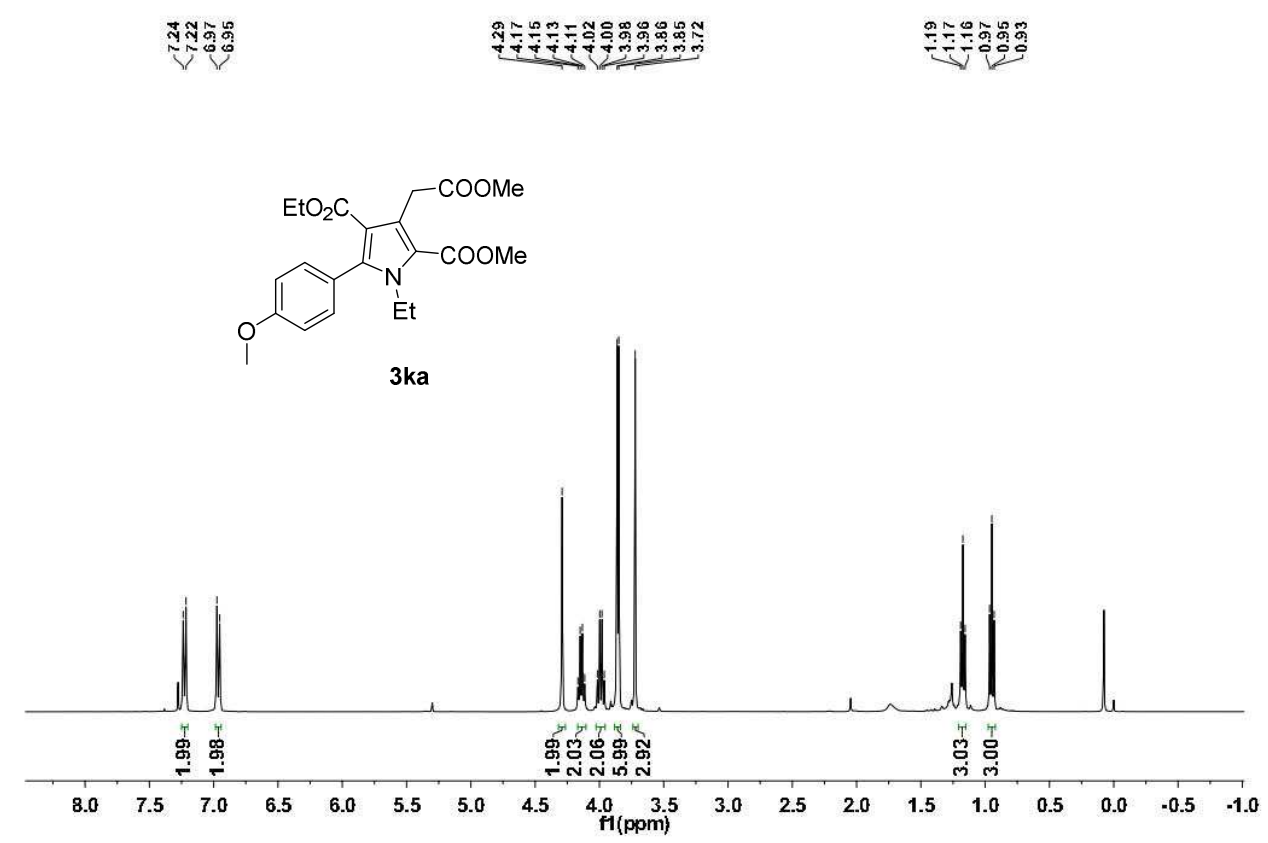

\section{${ }^{13} \mathrm{C}$ NMR spectrum of compound $3 \mathrm{ka}$}

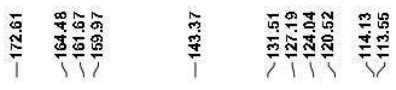

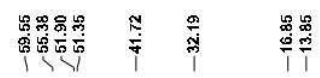
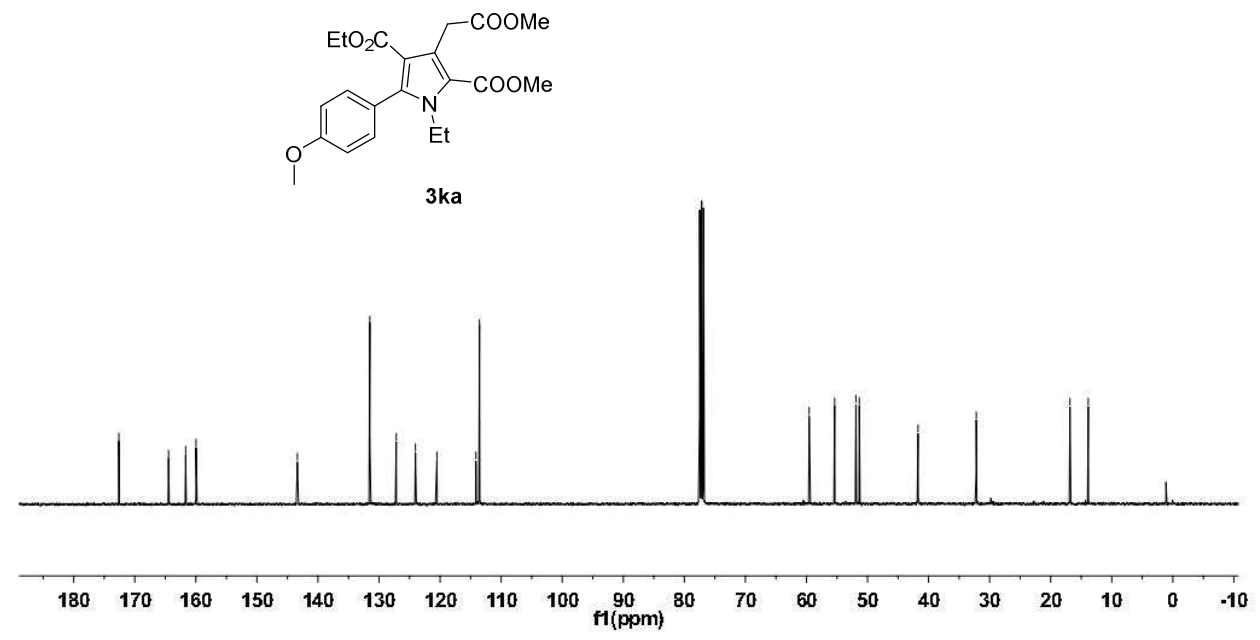
${ }^{1}$ H NMR spectrum of compound 3la
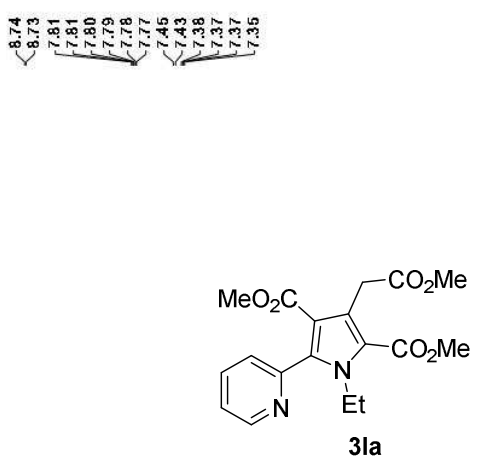

3la

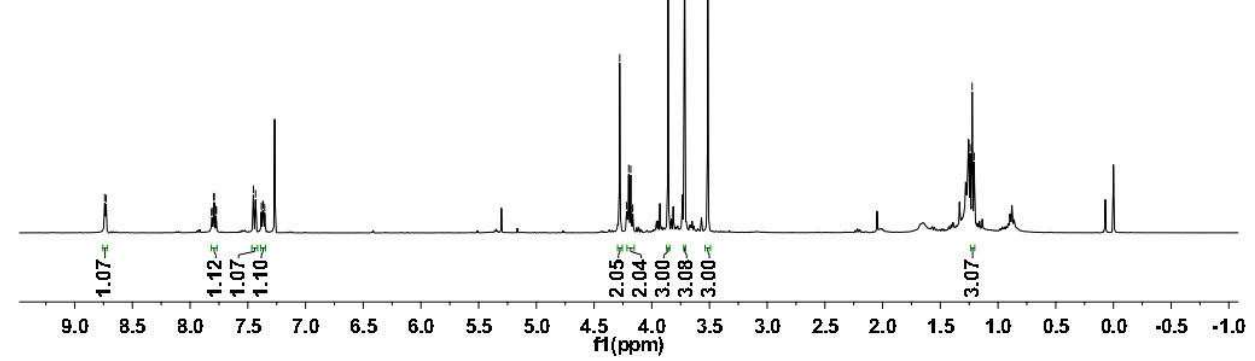

\section{${ }^{13}$ C NMR spectrum of compound 3la}
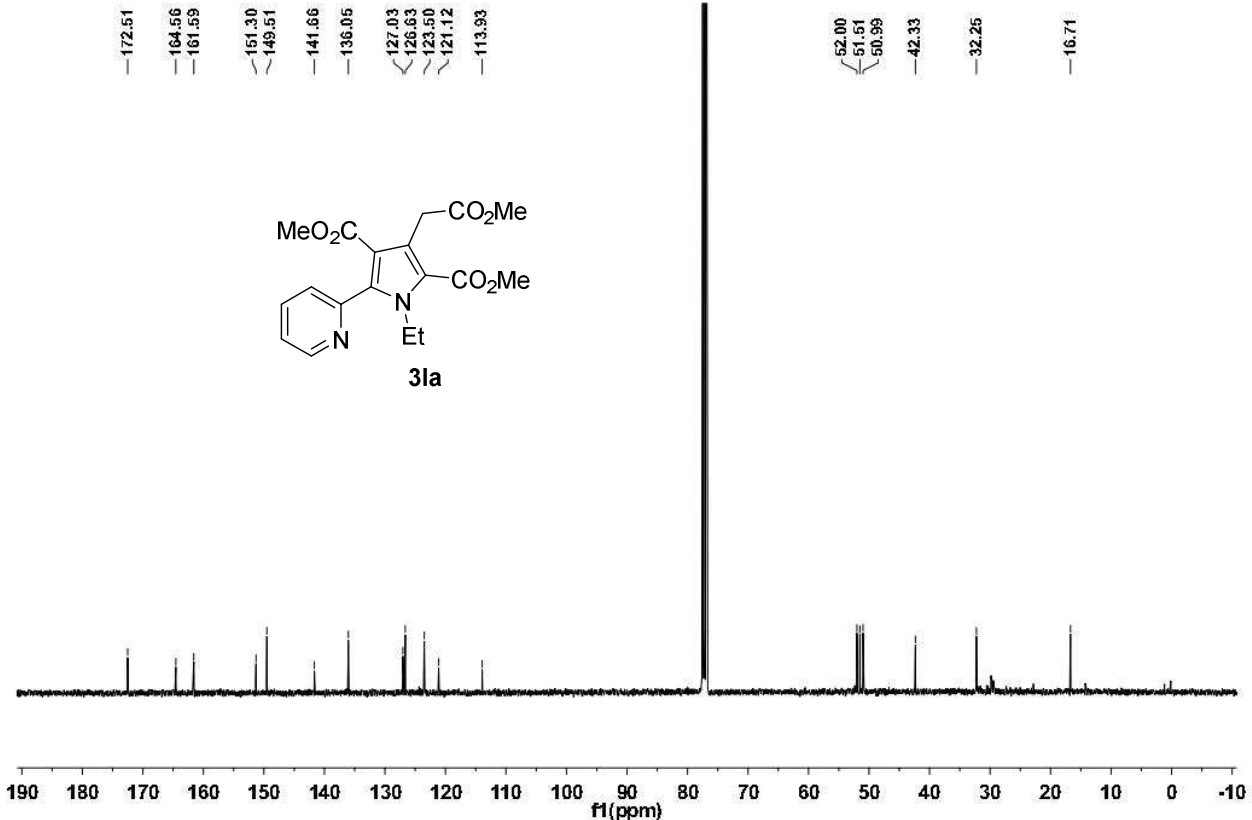
${ }^{1}$ H NMR spectrum of compound 3 ma

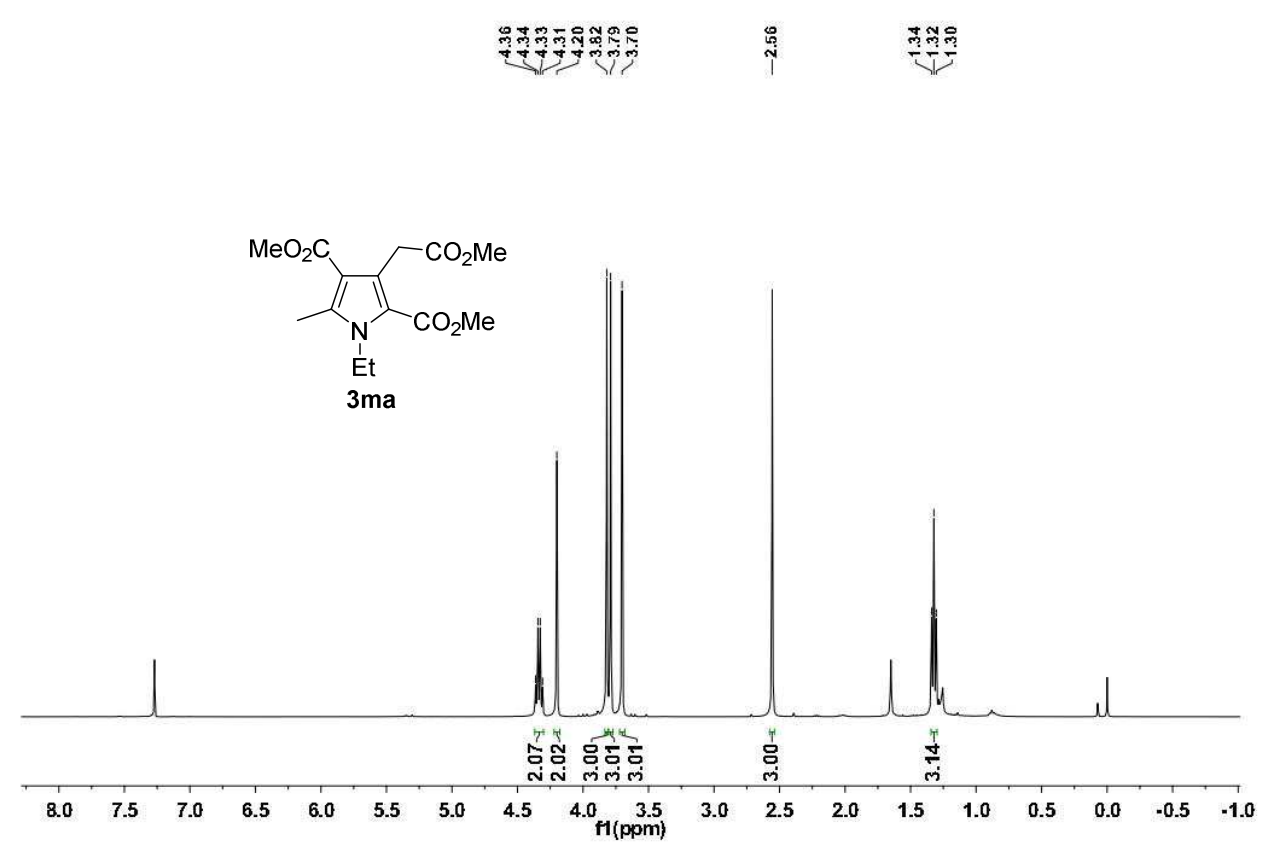

${ }^{13} \mathrm{C}$ NMR spectrum of compound $3 \mathrm{ma}$

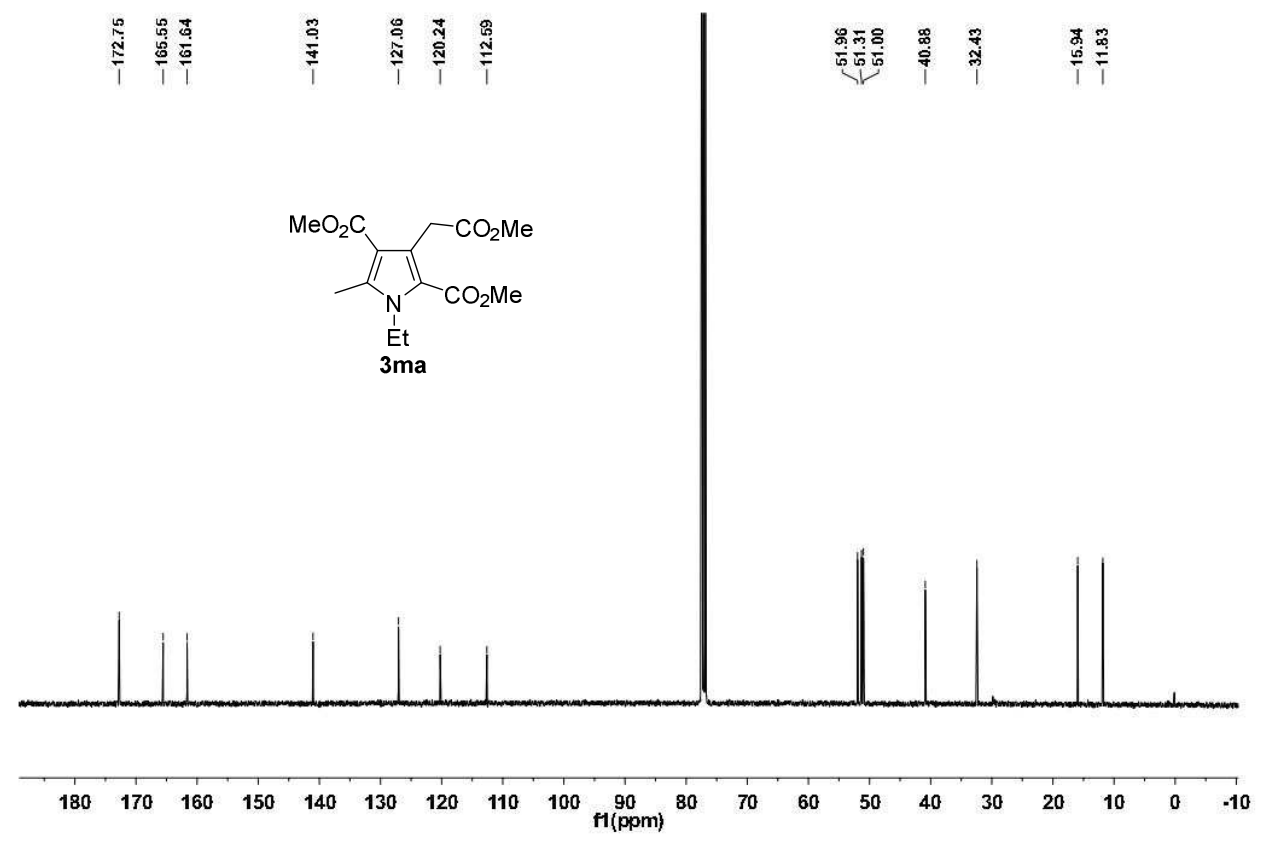


${ }^{1}$ H NMR spectrum of compound 3na
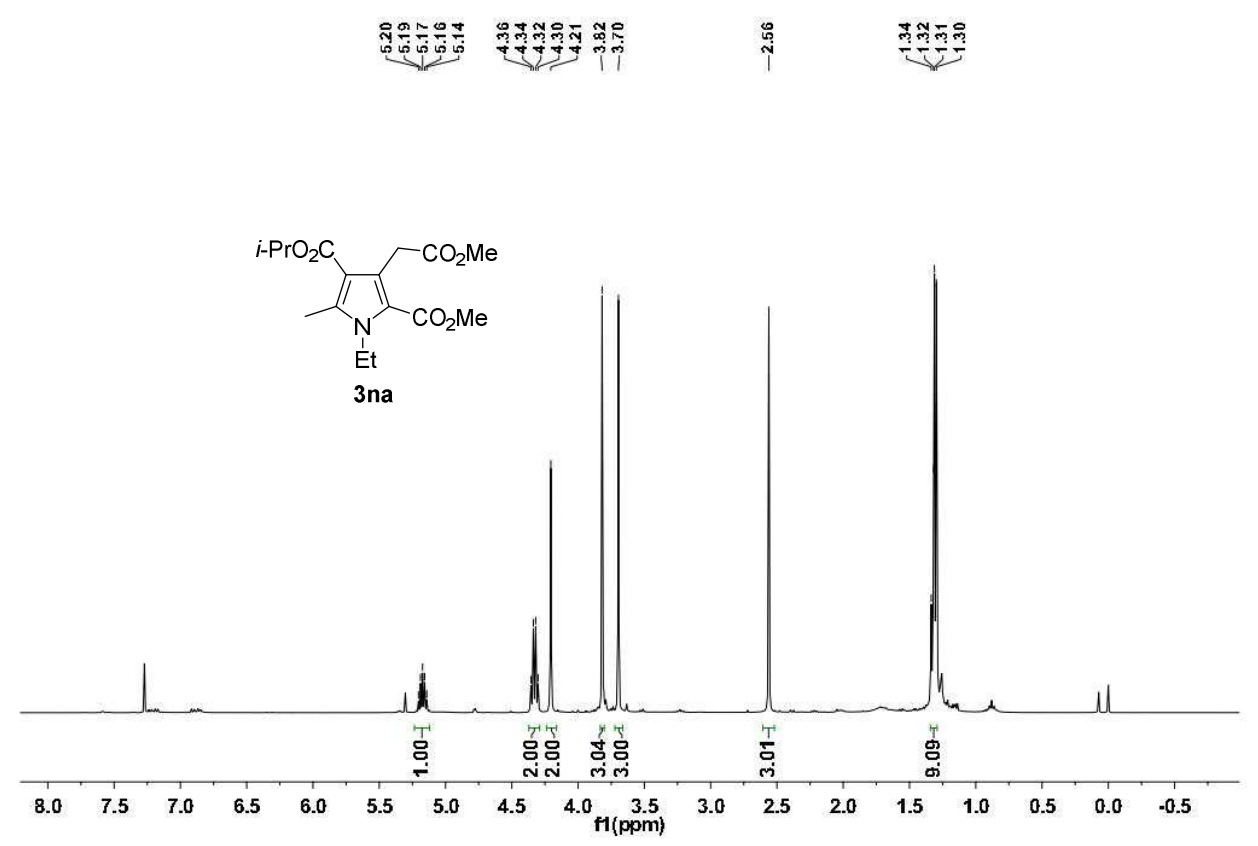

\section{${ }^{13}$ C NMR spectrum of compound 3na}

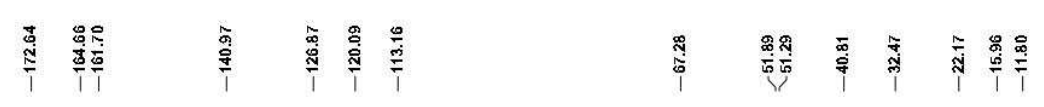

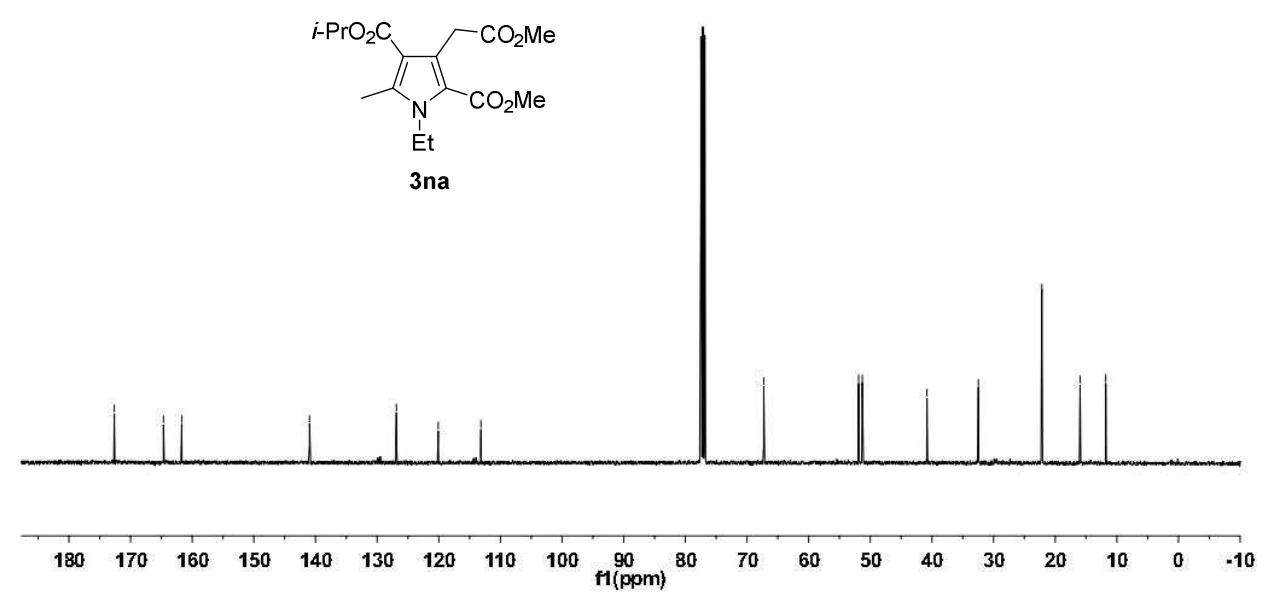


${ }^{1}$ H NMR spectrum of compound 3oa

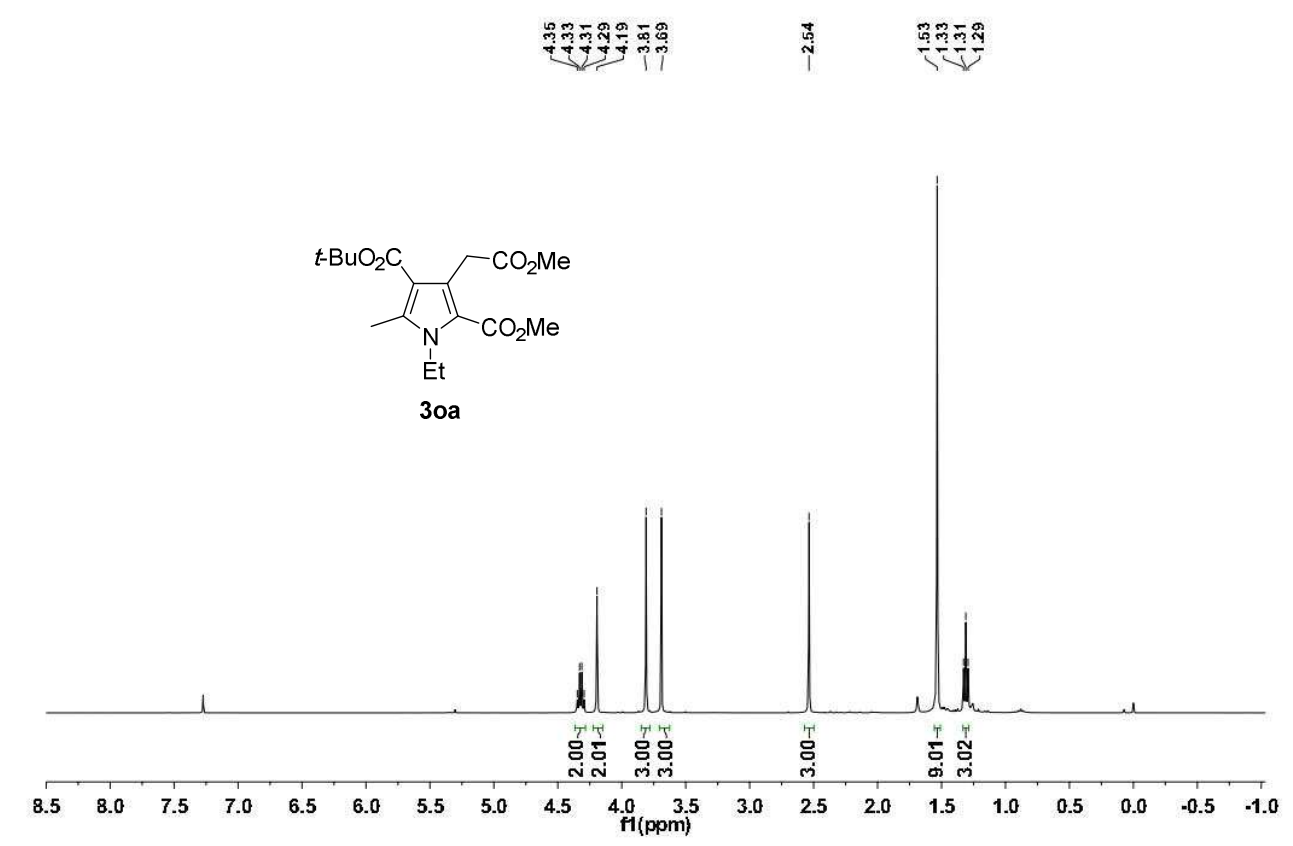

\section{${ }^{13} \mathrm{C}$ NMR spectrum of compound $30 a$}
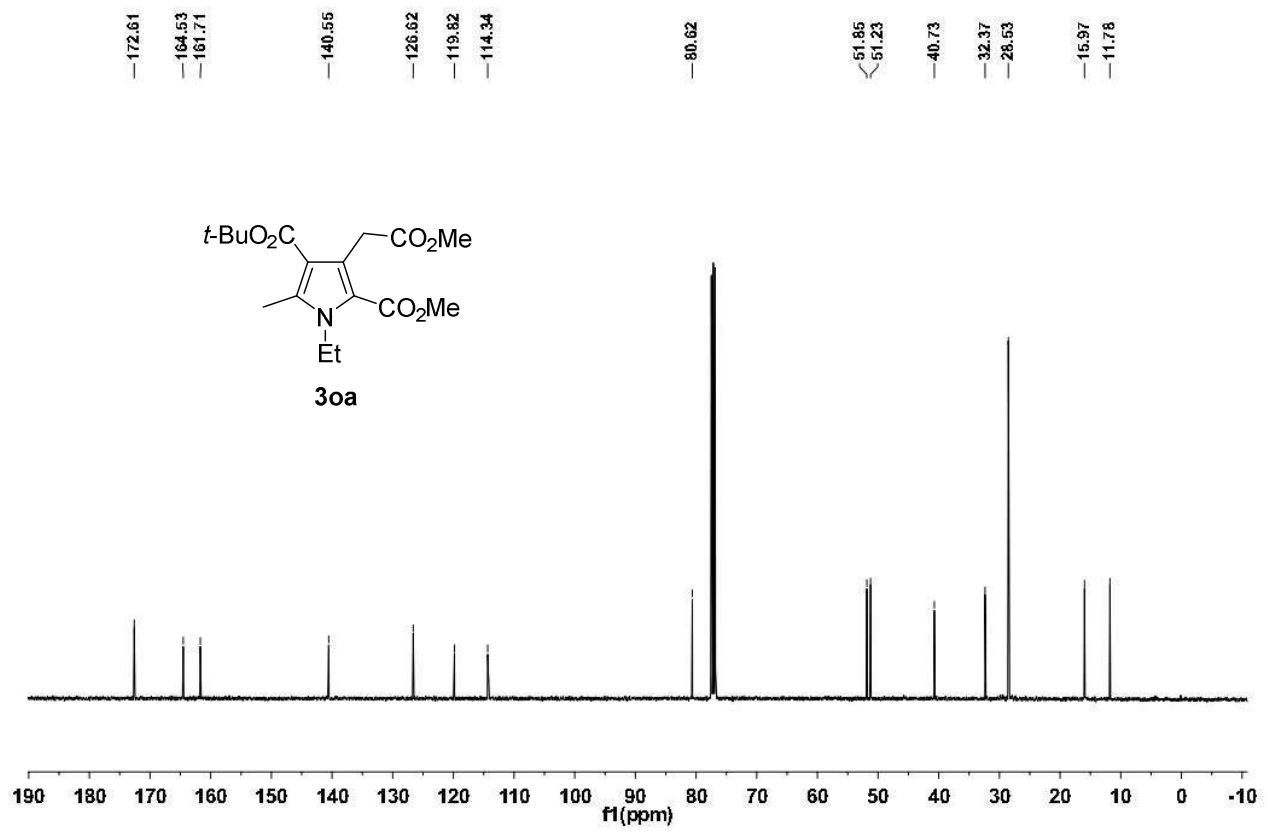
${ }^{1}$ H NMR spectrum of compound 3pa

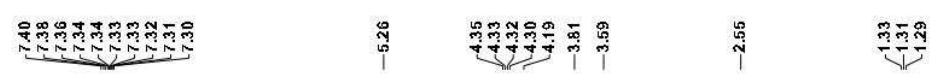
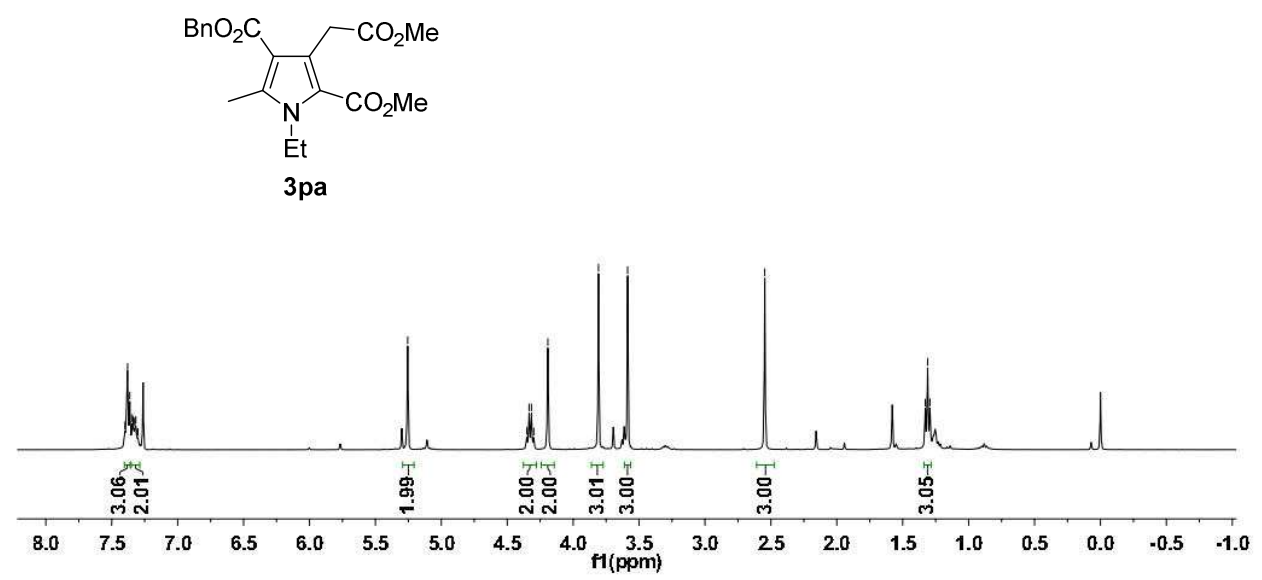

${ }^{13}$ C NMR spectrum of compound 3pa

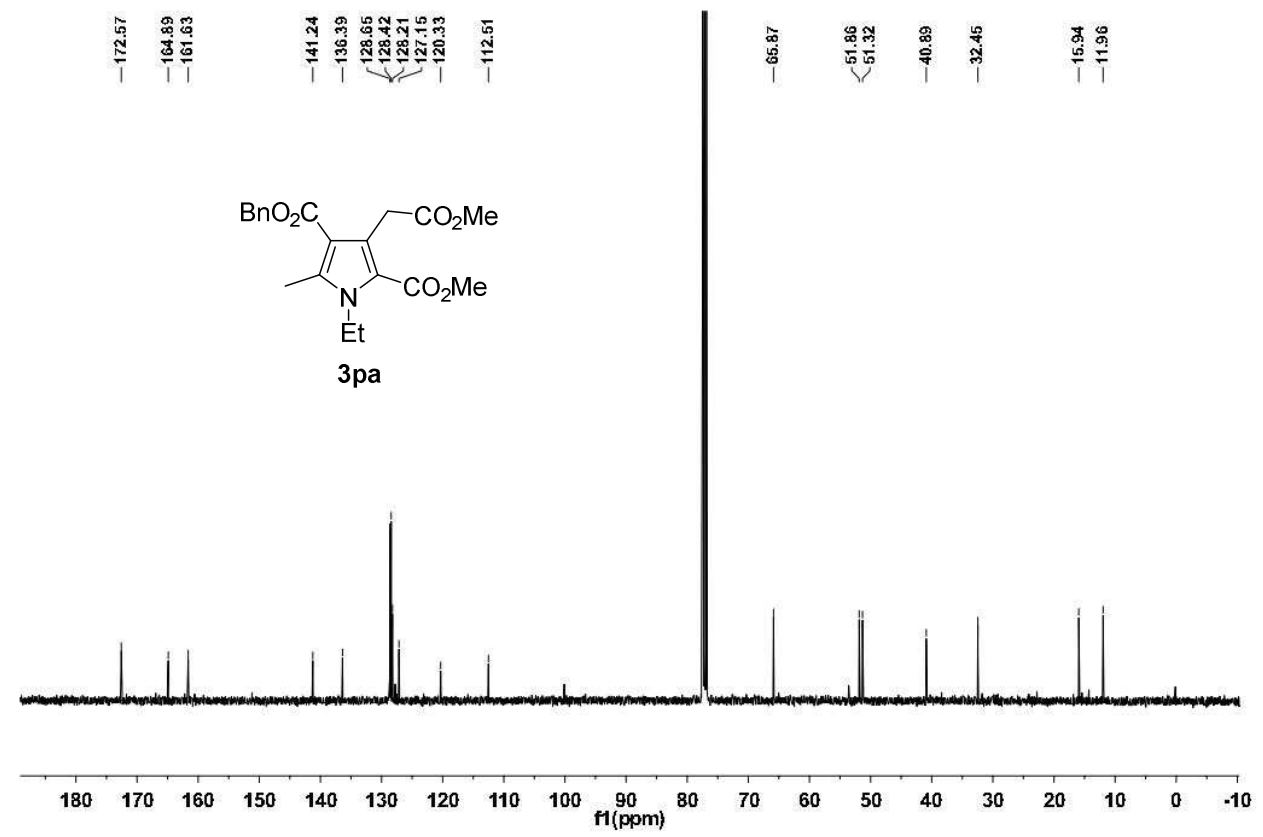


${ }^{1}$ H NMR spectrum of compound 3qa

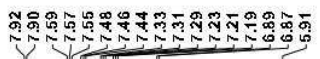

3qa

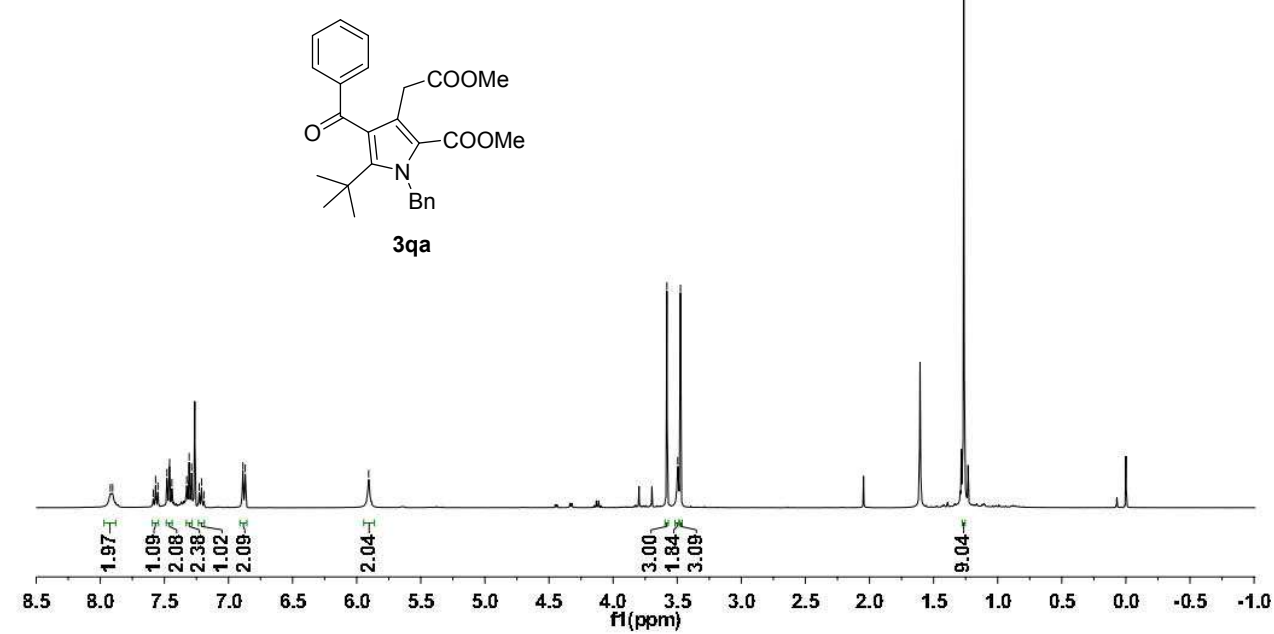

\section{${ }^{13} \mathrm{C}$ NMR spectrum of compound 3qa}
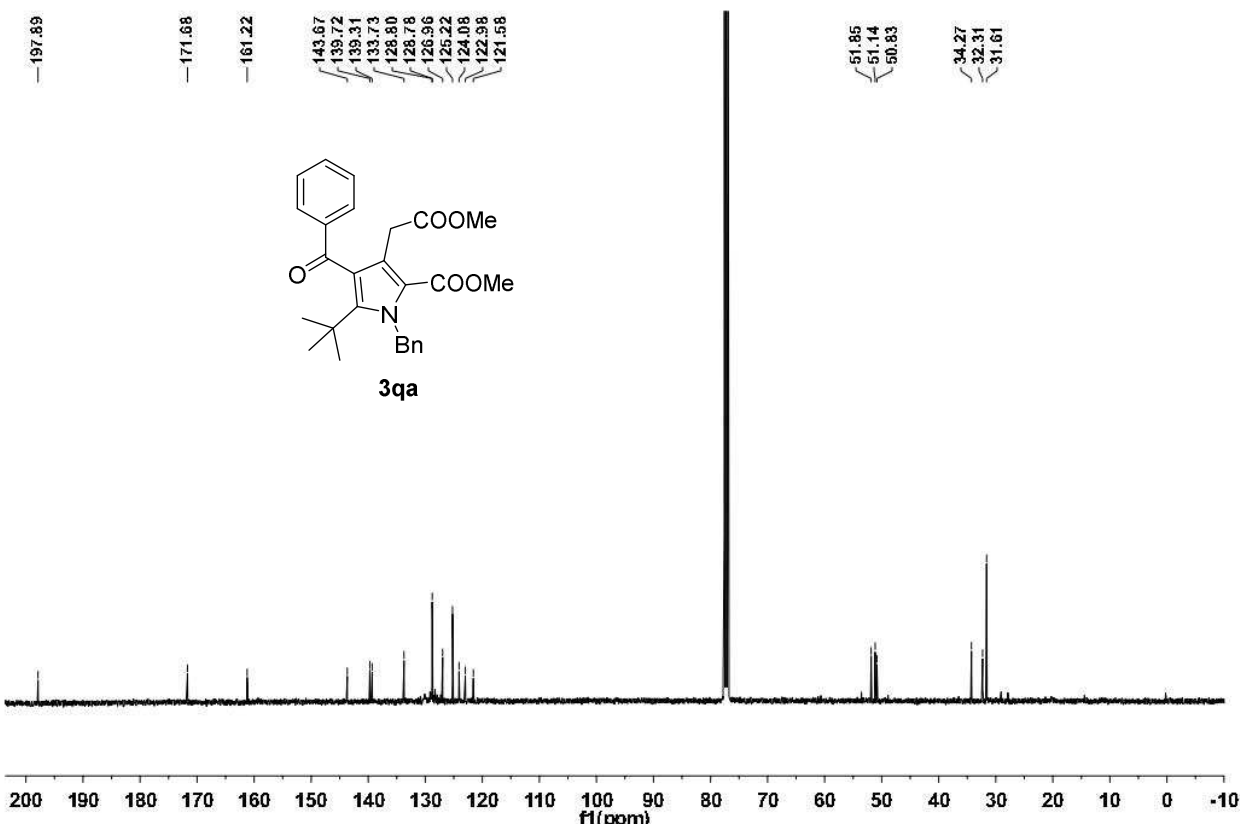
${ }^{1}$ H NMR spectrum of compound 3ra

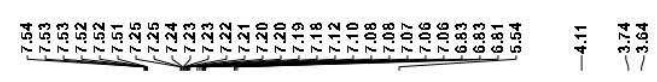

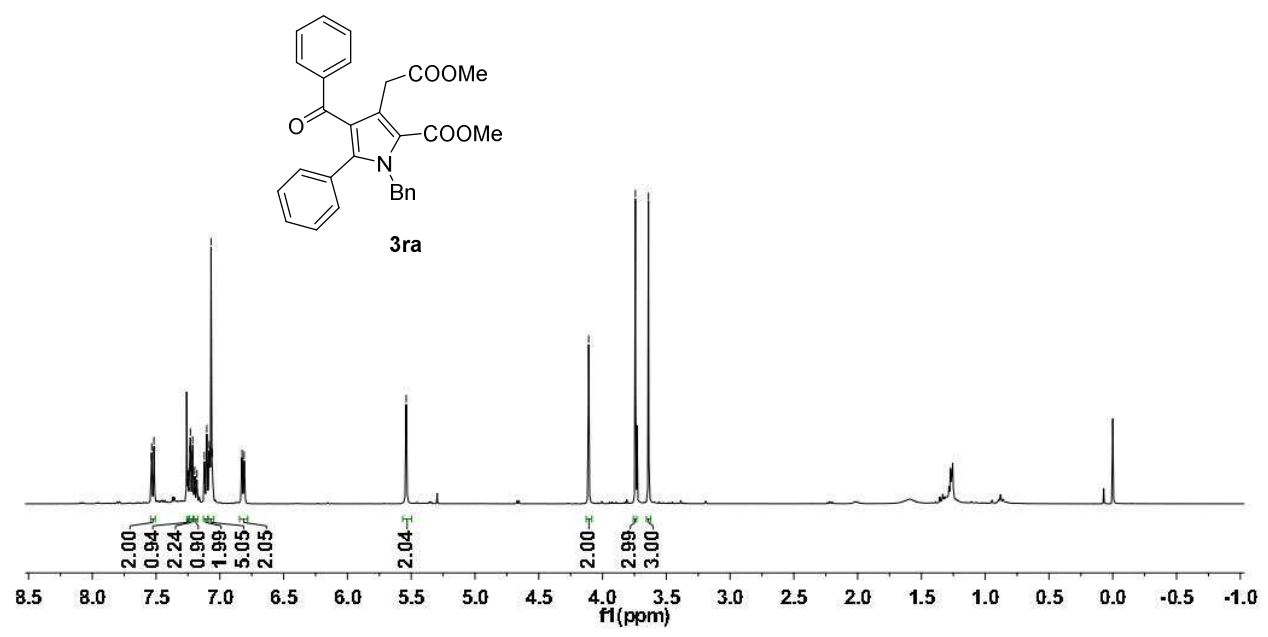

\section{${ }^{13}$ C NMR spectrum of compound 3ra}
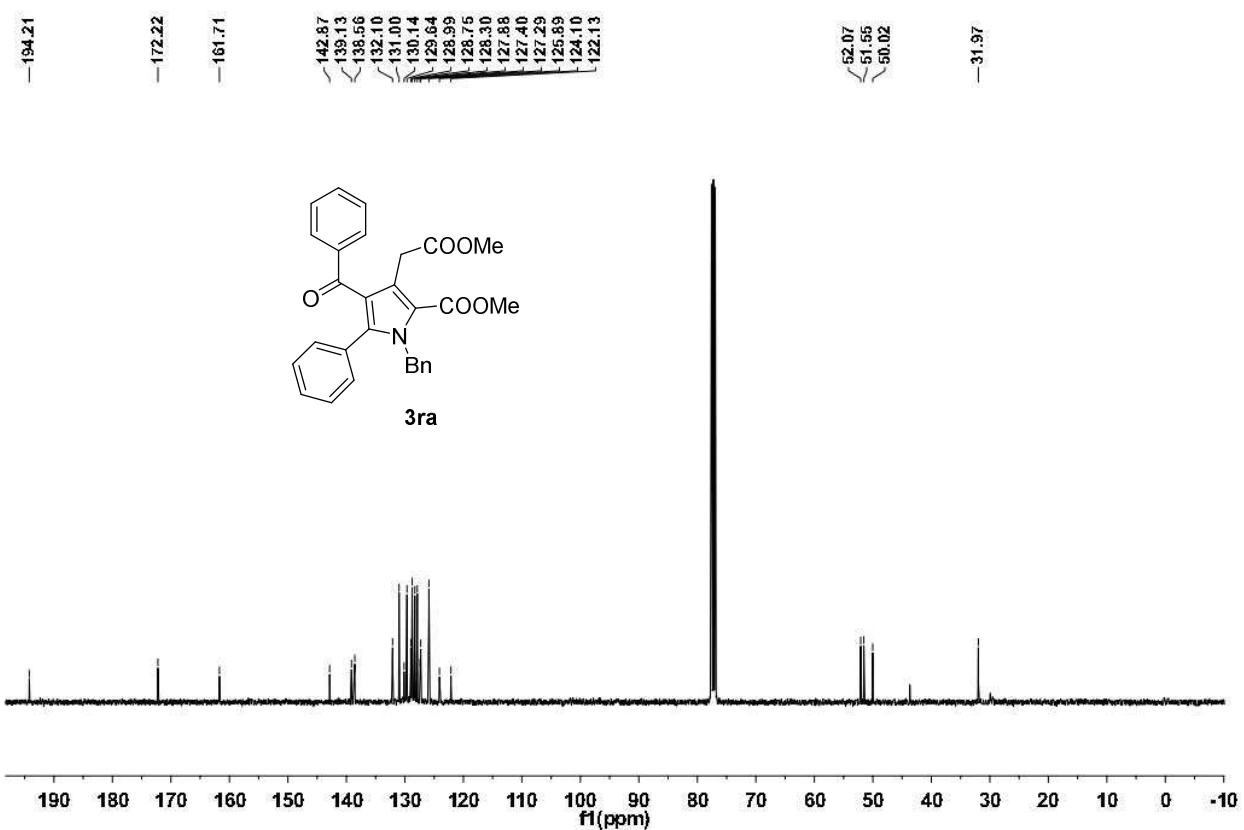
${ }^{1} \mathrm{H}$ NMR spectrum of compound $3 \mathrm{mb}$
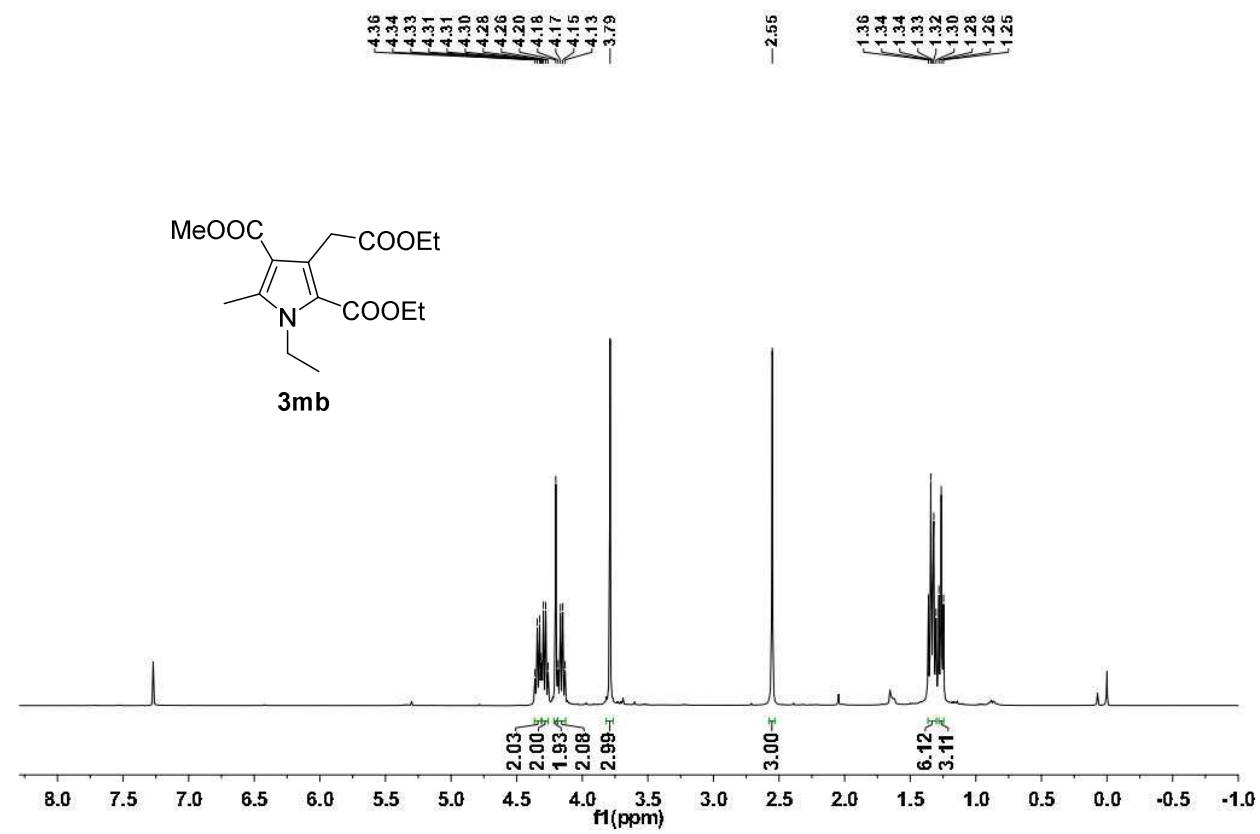

${ }^{13} \mathrm{C}$ NMR spectrum of compound $3 \mathrm{mb}$

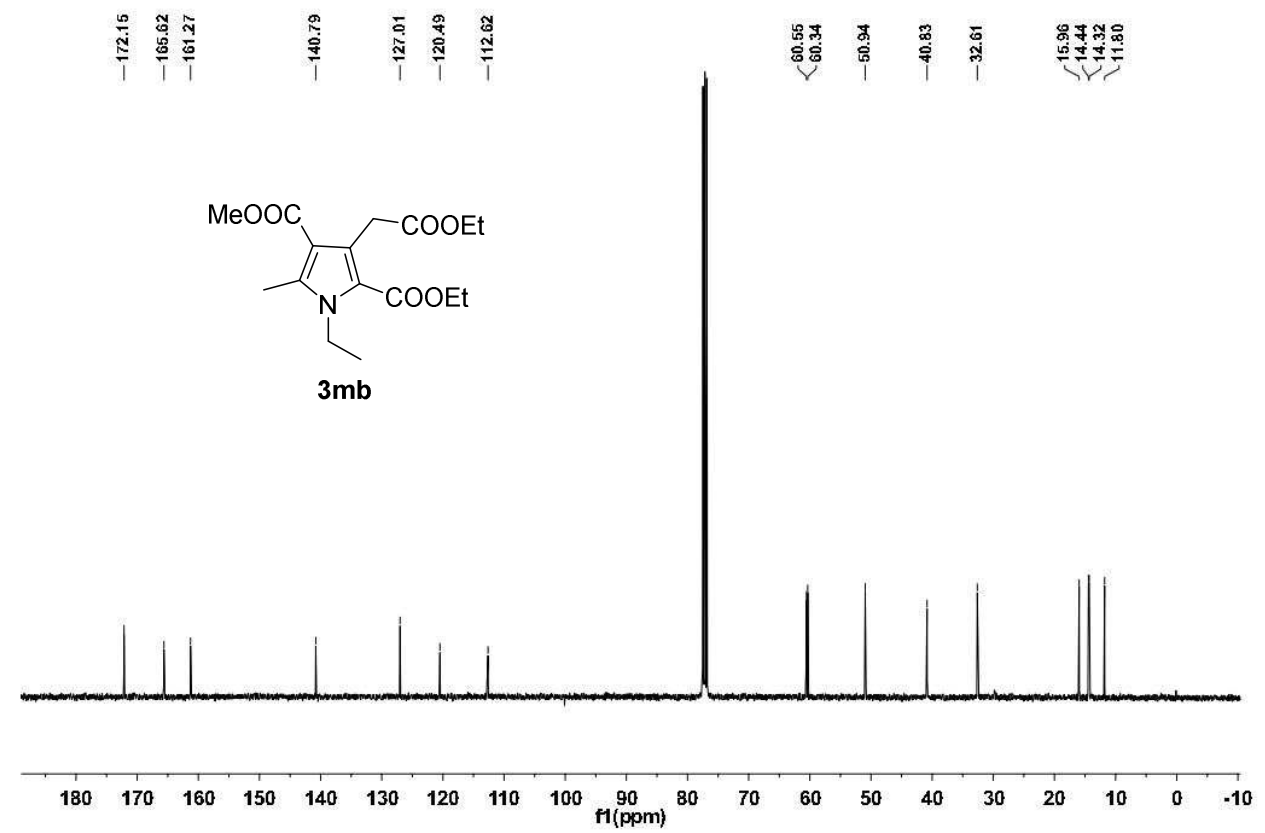


${ }^{1} \mathrm{H}$ NMR spectrum of compound $3 \mathrm{mc}$
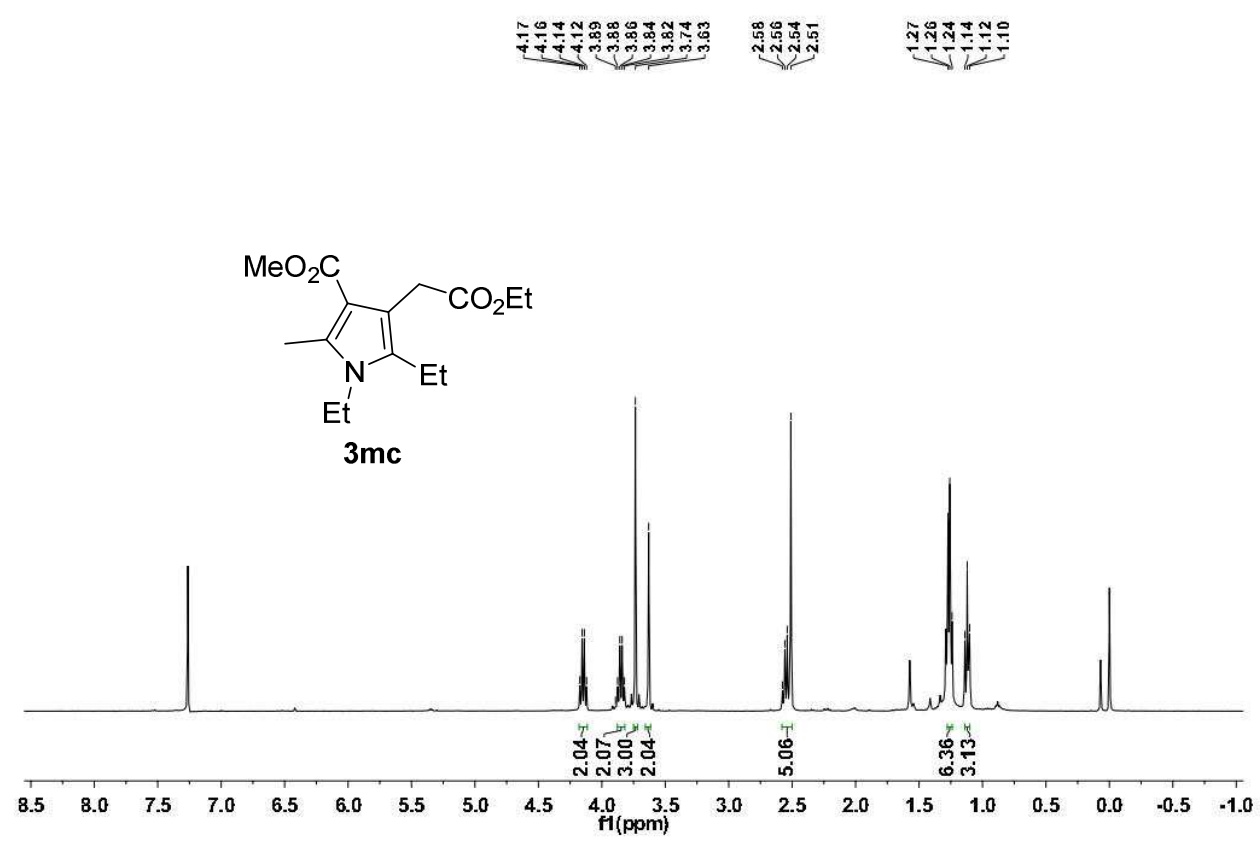

${ }^{13} \mathrm{C}$ NMR spectrum of compound $3 \mathrm{mc}$

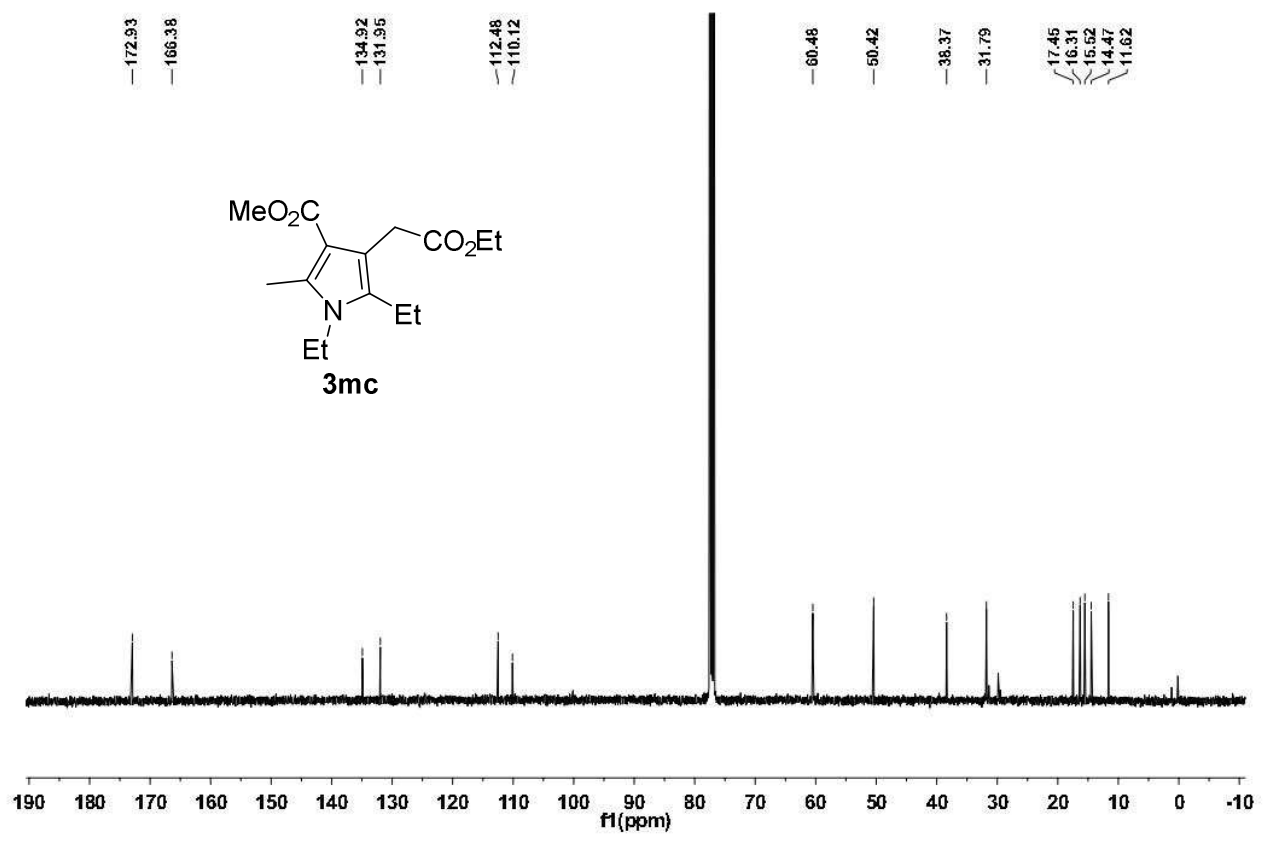


${ }^{1}$ H NMR spectrum of compound 3md
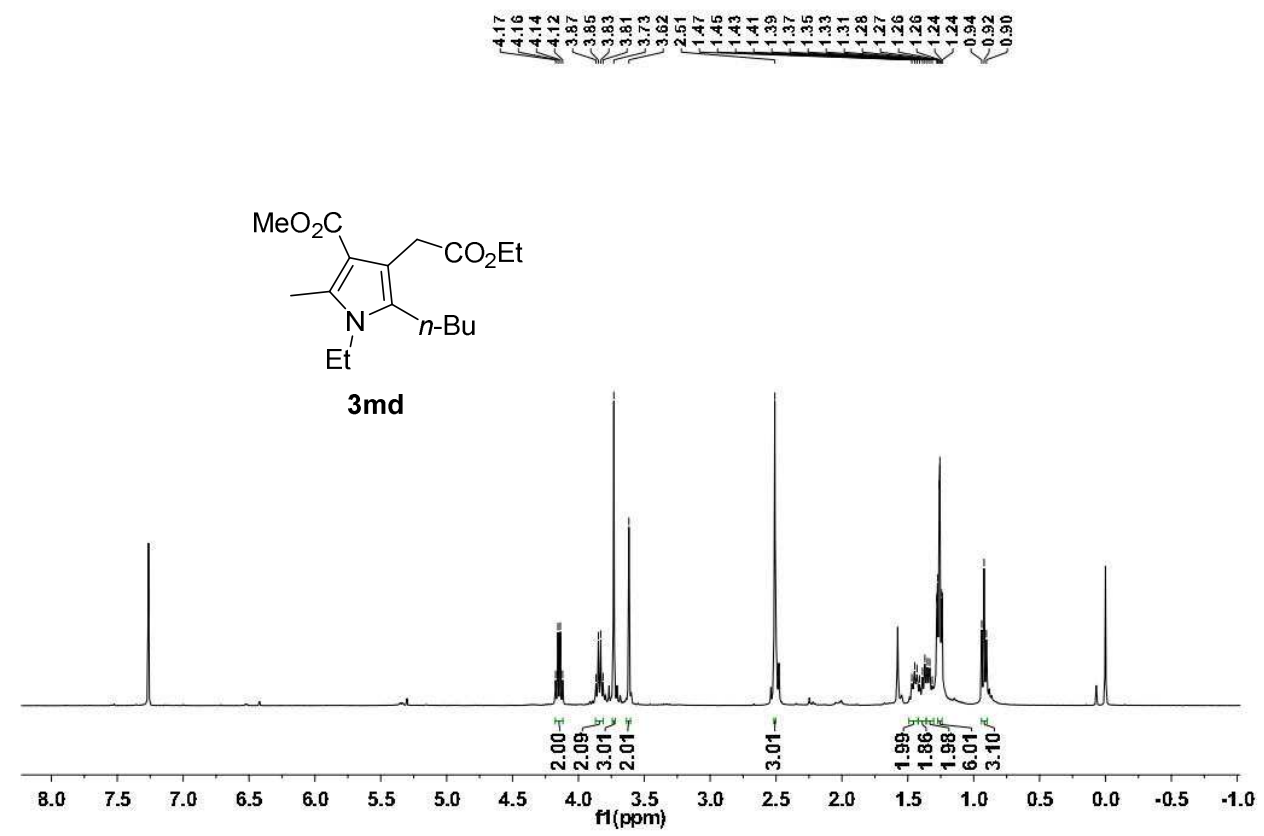

${ }^{13} \mathrm{C}$ NMR spectrum of compound $3 \mathrm{md}$

空

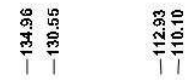

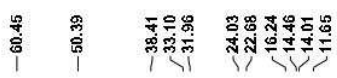

$\mathrm{MeO}_{2} \mathrm{C}$
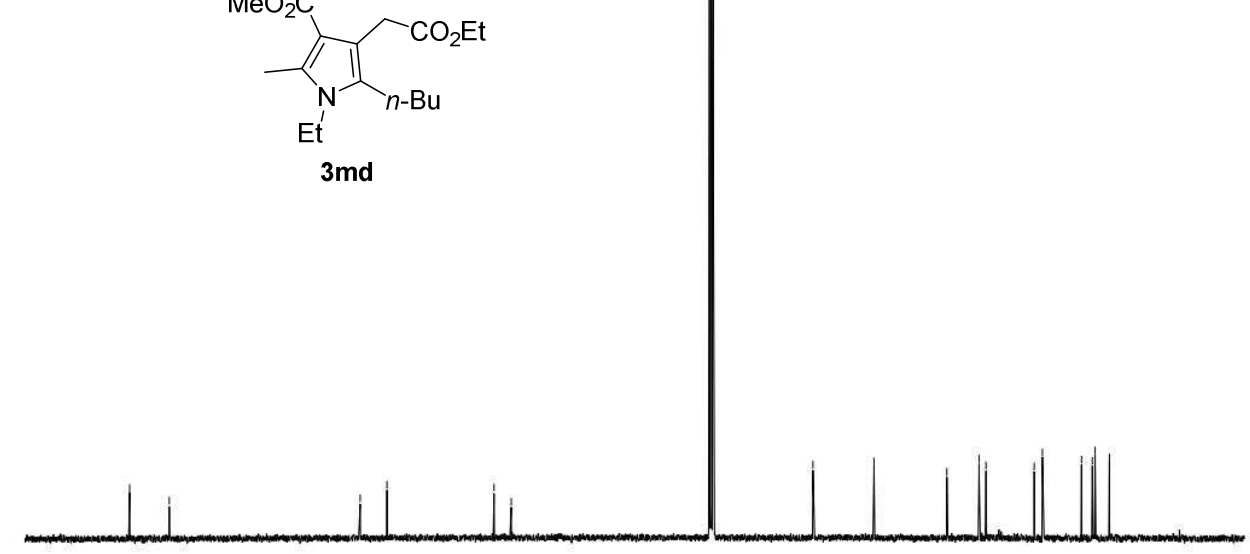

$190 \begin{array}{llllllllllllllllllllllllll}180 & 170 & 160 & 150 & 140 & 130 & 120 & 110 & 100 & 90 & 80 & 70 & 60 & 50 & 40 & 30 & 20 & 10 & 0 & -10\end{array}$ 
${ }^{1}$ H NMR spectrum of compound 3 me

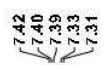

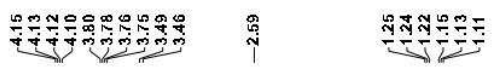
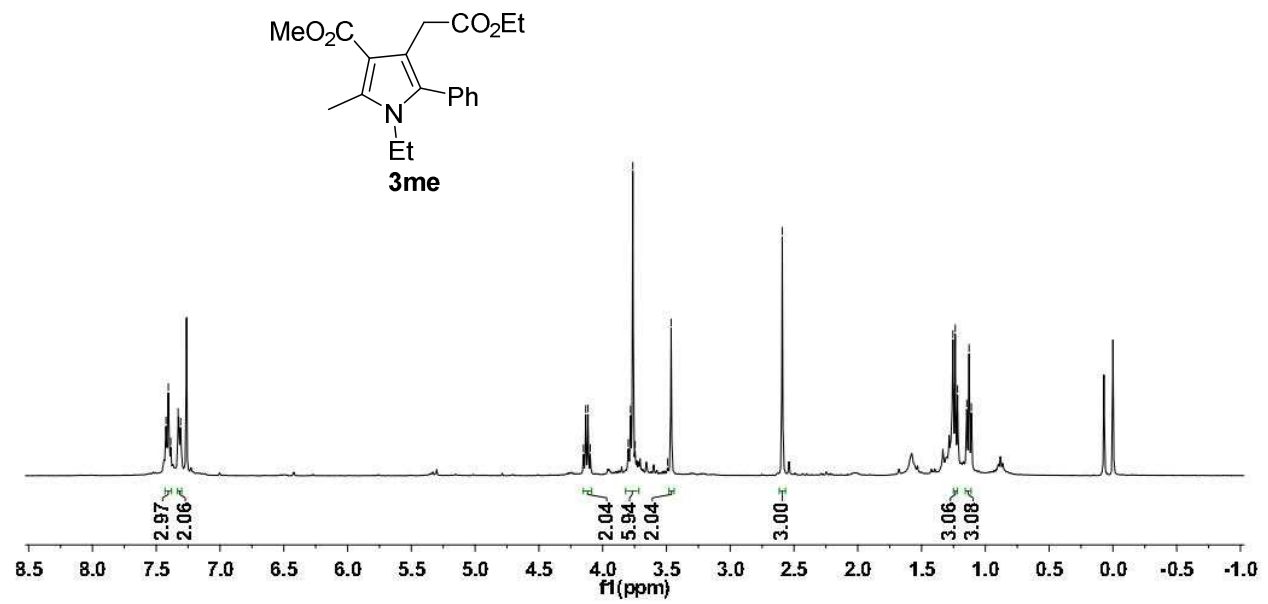

\section{${ }^{13} \mathrm{C}$ NMR spectrum of compound $3 \mathrm{me}$}
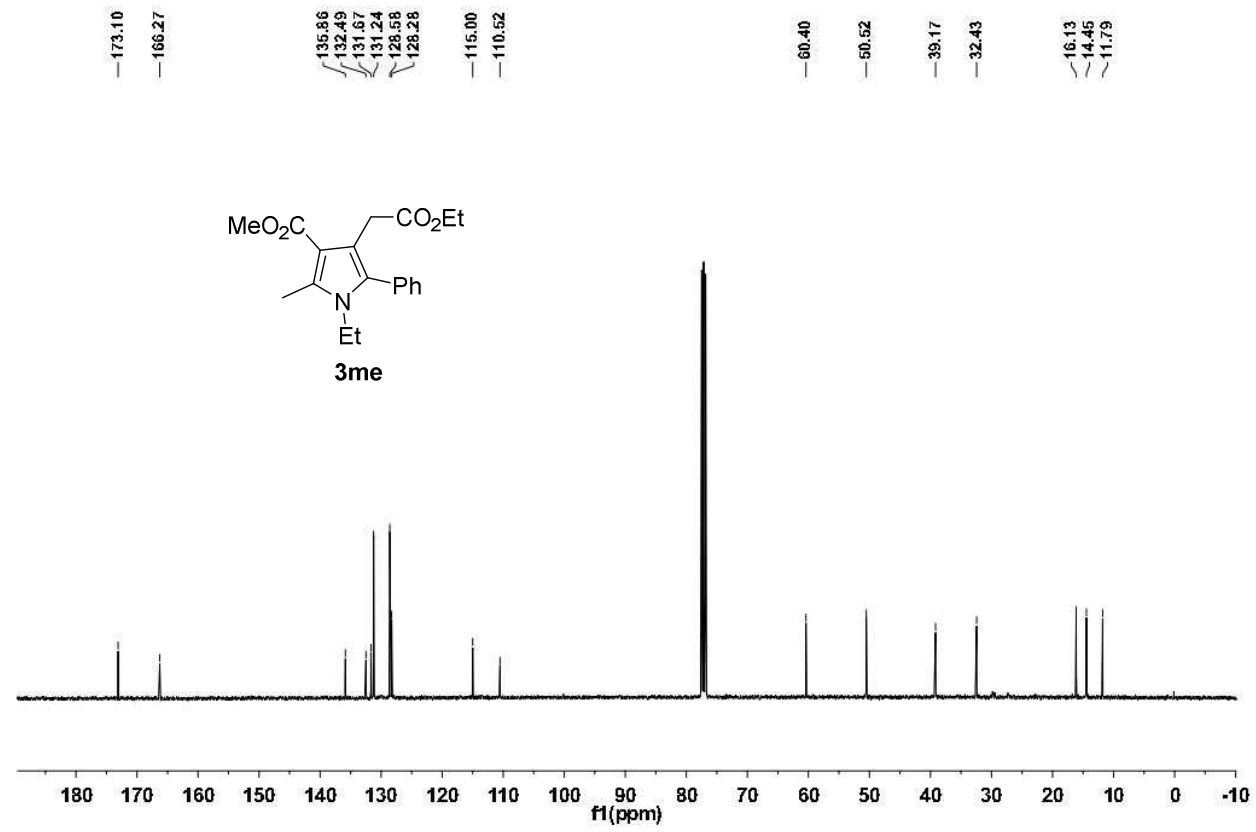
${ }^{1}$ H NMR spectrum of compound $3 \mathrm{mf}$

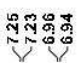

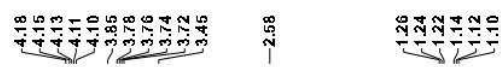

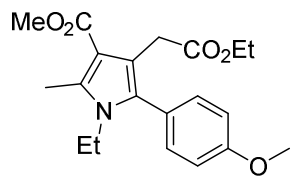

$3 \mathrm{mf}$

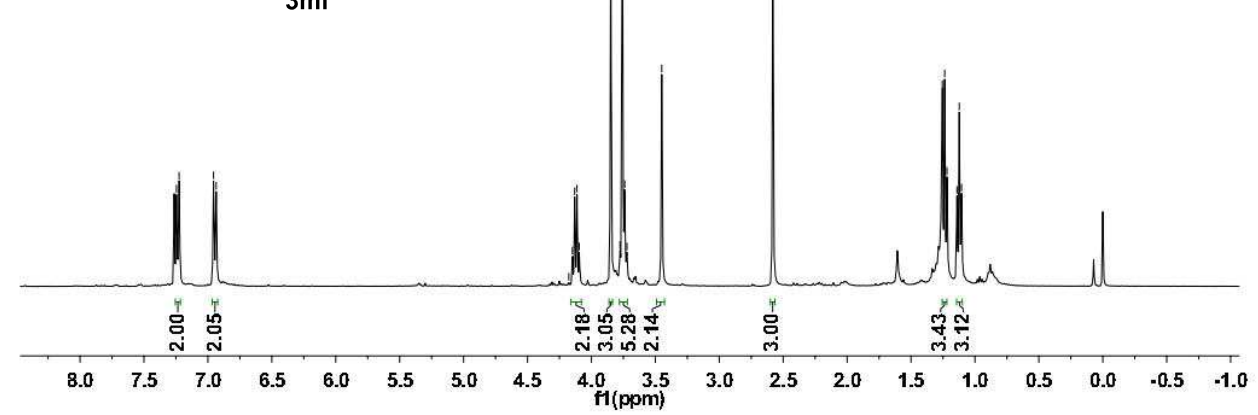

${ }^{13} \mathrm{C}$ NMR spectrum of compound $3 \mathrm{mf}$

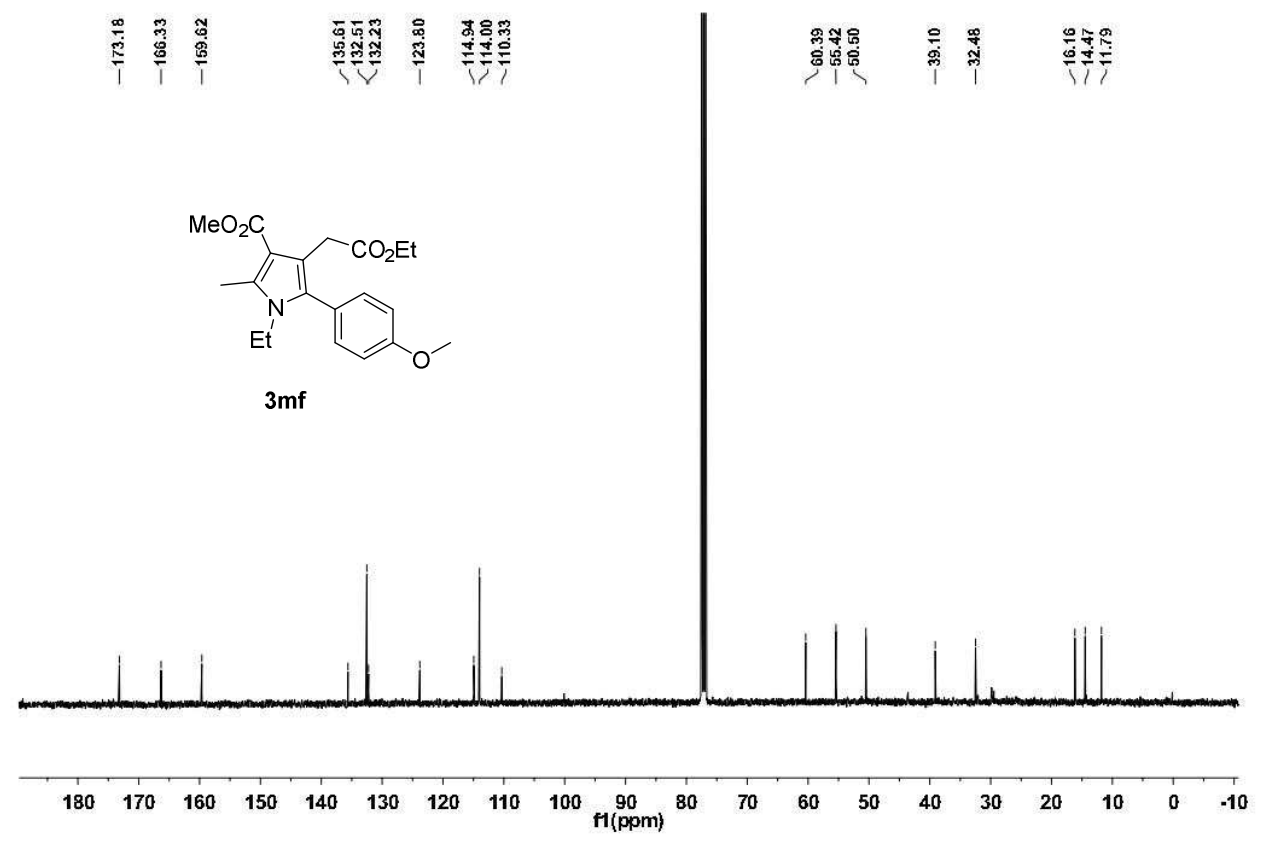


${ }^{1}$ H NMR spectrum of compound $3 \mathrm{mg}$

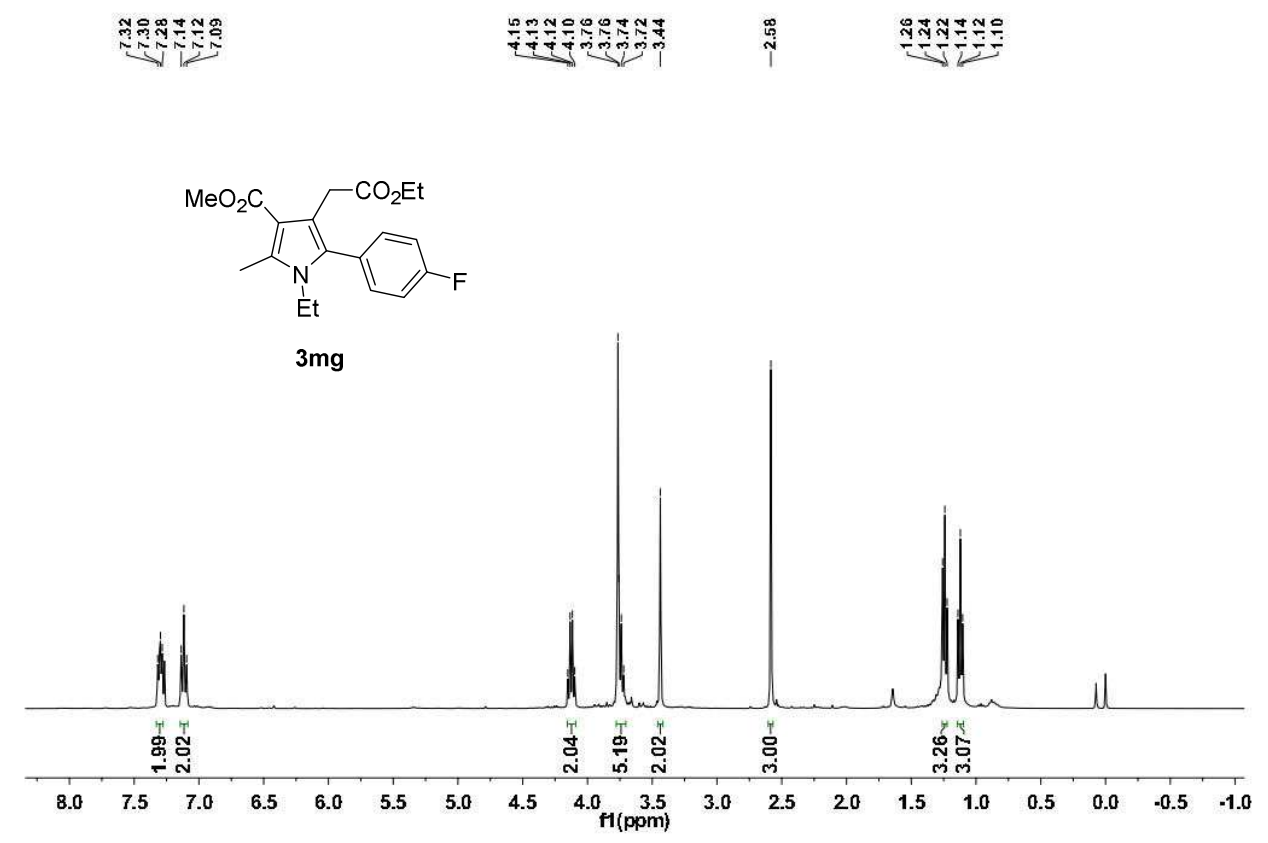

${ }^{13} \mathrm{C}$ NMR spectrum of compound $3 \mathrm{mg}$

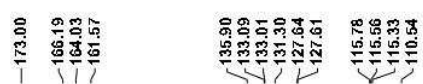

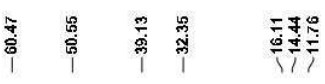

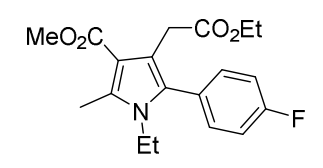

$3 \mathrm{mg}$

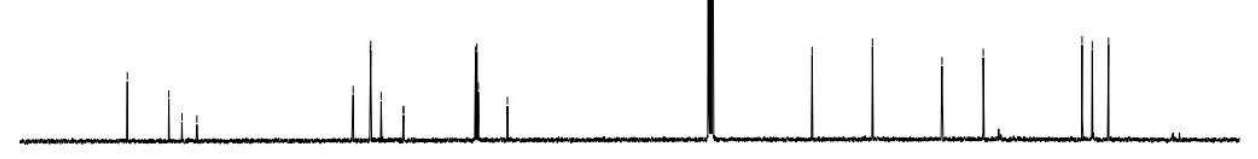

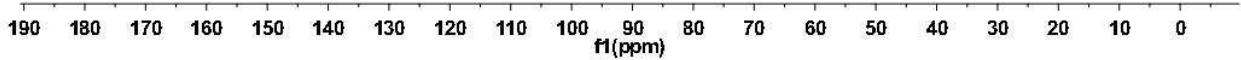


${ }^{1}$ H NMR spectrum of compound $3 \mathrm{mh}$
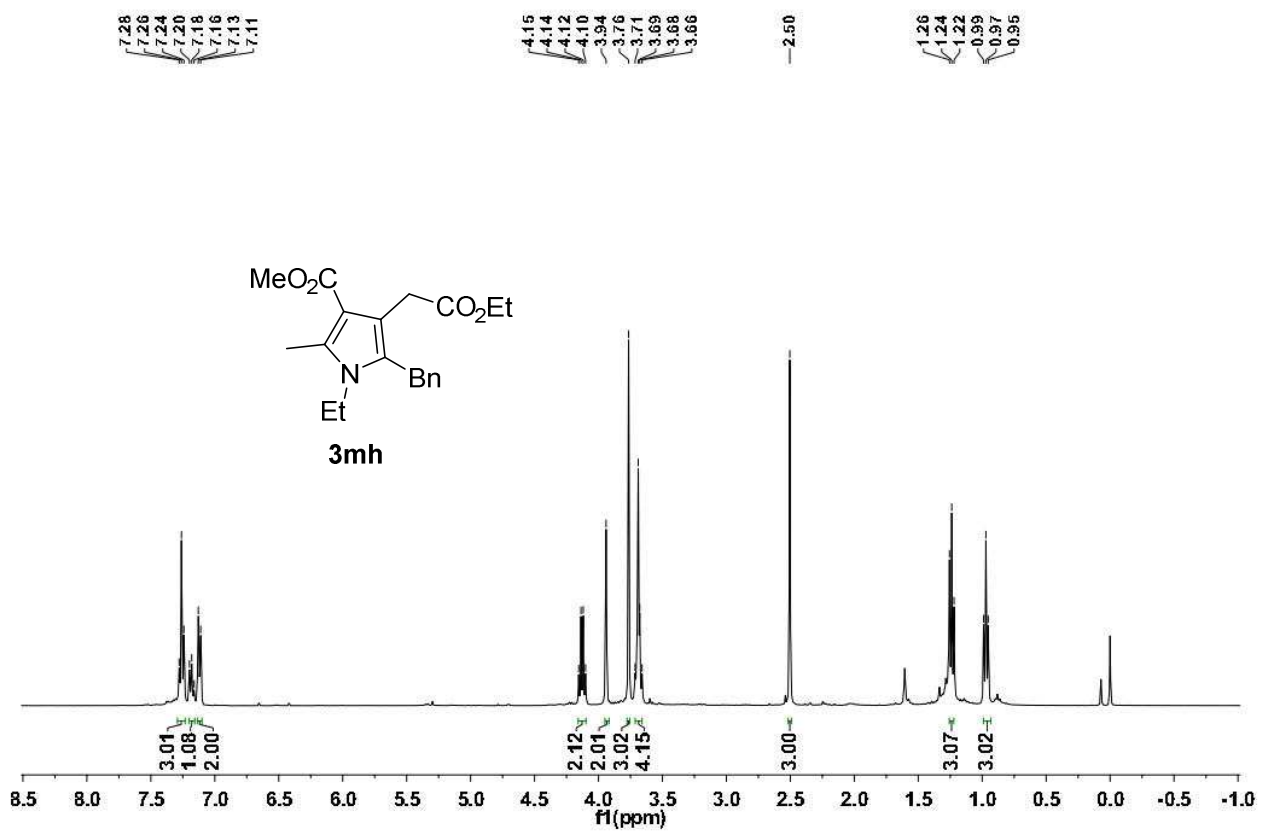

${ }^{13} \mathrm{C}$ NMR spectrum of compound $3 \mathrm{mh}$

స

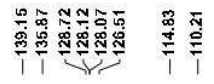

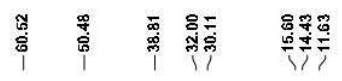

$\mathrm{MeO}_{2} \mathrm{C}$

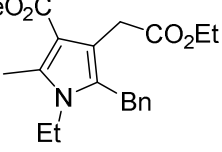

$3 \mathrm{mh}$

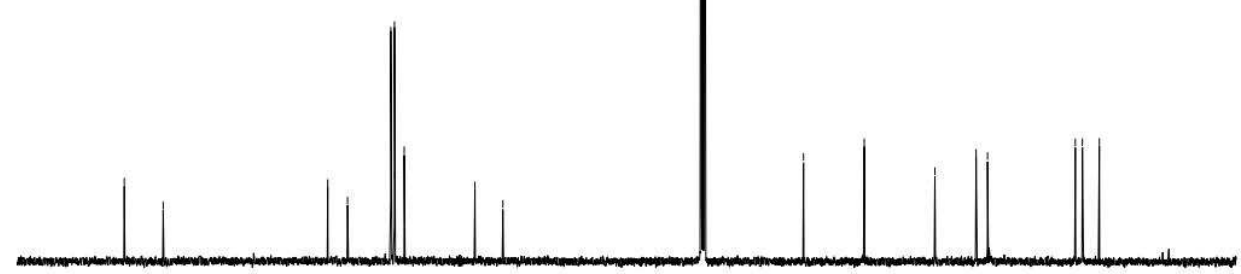

\begin{tabular}{rllllllllllllllllllllllll}
\hline 190 & 180 & 170 & 160 & 150 & 140 & 130 & 120 & 110 & 100 & 90 & 80 & 70 & 60 & 50 & 40 & 30 & 20 & 10 & 0 & -10
\end{tabular} 


\section{X-Ray structure of $\mathbf{3 m h}$ and the corresponding data}

CCDC 1479624 (3mh), contain the supplementary crystallographic data for this paper. These data can be obtained free of charge from the Cambridge Crystallographic Data Centre via www.ccdc.cam.ac.uk/data_request/cif.

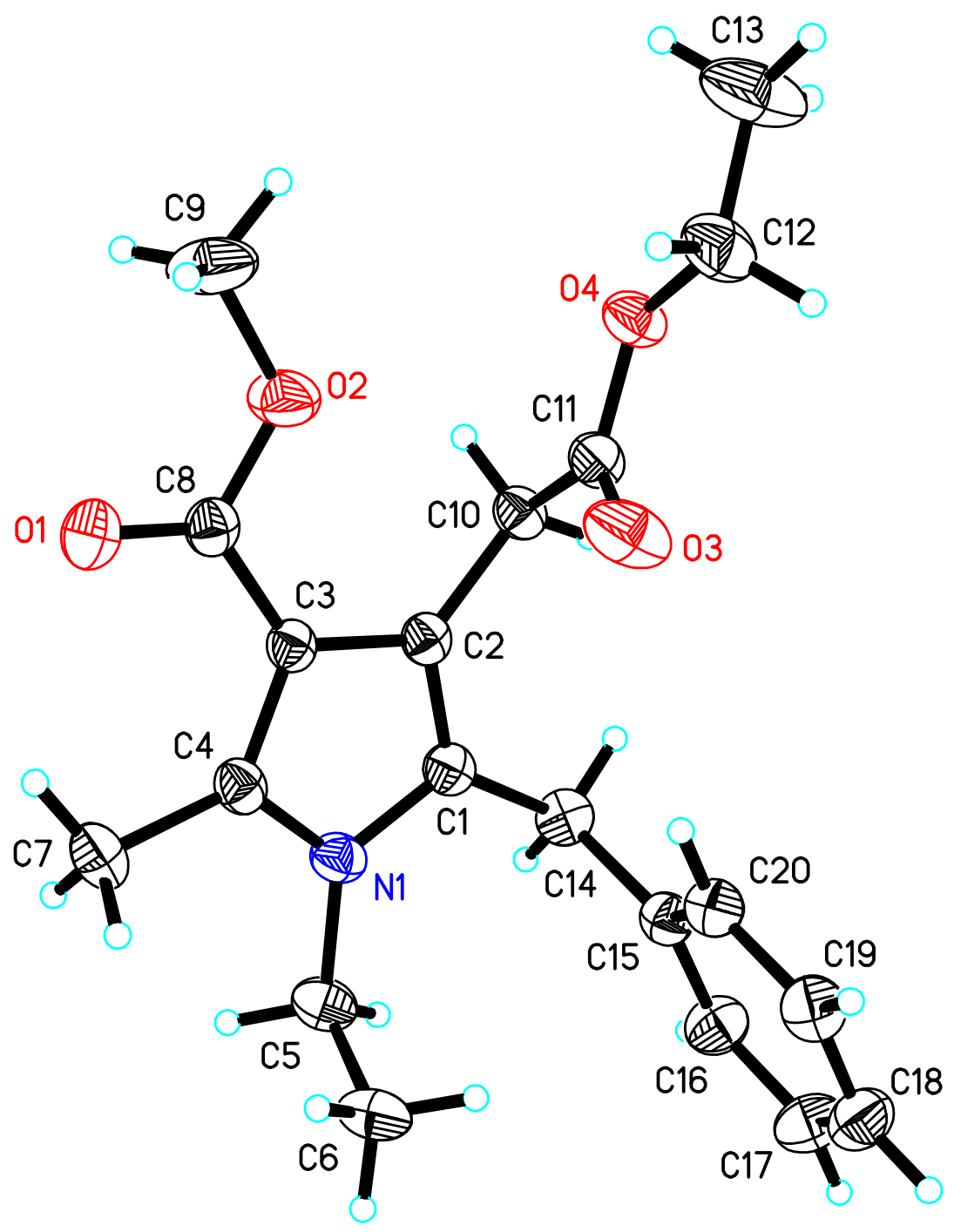

Figure 1. ORTEP diagram of compound $\mathbf{3 m h}$. Ellipsoids are drawn at the $30 \%$ probability level.

Empirical formula

Formula weight

Temperature
$\mathrm{C} 20 \mathrm{H} 25 \mathrm{~N} \mathrm{O} 4$

343.41

273(2) K 


\begin{tabular}{|c|c|c|}
\hline Wavelength & \multicolumn{2}{|l|}{$0.71073 \AA$} \\
\hline Crystal system & \multicolumn{2}{|l|}{ Monoclinic } \\
\hline Space group & \multicolumn{2}{|l|}{ P 21} \\
\hline \multirow[t]{3}{*}{ Unit cell dimensions } & $a=10.6905(12) \AA$ & $\alpha=90^{\circ}$ \\
\hline & $\mathrm{b}=7.8348(9) \AA$ & $\beta=102.791(2)^{\circ}$. \\
\hline & $\mathrm{c}=11.6180(13) \AA$ & $\gamma=90^{\circ}$ \\
\hline Volume & \multicolumn{2}{|l|}{$948.95(19) \AA^{3}$} \\
\hline $\mathrm{Z}$ & \multicolumn{2}{|l|}{2} \\
\hline Density (calculated) & \multicolumn{2}{|l|}{$1.202 \mathrm{Mg} / \mathrm{m}^{3}$} \\
\hline Absorption coefficient & \multicolumn{2}{|l|}{$0.083 \mathrm{~mm}^{-1}$} \\
\hline $\mathrm{F}(000)$ & \multicolumn{2}{|l|}{368} \\
\hline Crystal size & \multicolumn{2}{|c|}{$0.200 \times 0.160 \times 0.130 \mathrm{~mm}^{3}$} \\
\hline Theta range for data collection & \multicolumn{2}{|l|}{1.797 to $25.996^{\circ}$} \\
\hline Index ranges & \multicolumn{2}{|c|}{$-13<=\mathrm{h}<=12,-9<=\mathrm{k}<=9,-13<=\mathrm{l}<=14$} \\
\hline Reflections collected & \multicolumn{2}{|l|}{6962} \\
\hline Independent reflections & \multicolumn{2}{|c|}{$3585[\mathrm{R}(\mathrm{int})=0.0200]$} \\
\hline Completeness to theta $=25.242^{\circ}$ & \multicolumn{2}{|l|}{$100.0 \%$} \\
\hline Absorption correction & \multicolumn{2}{|c|}{ Semi-empirical from equivalents } \\
\hline Max. and min. transmission & \multicolumn{2}{|l|}{0.7456 and 0.6676} \\
\hline Refinement method & \multicolumn{2}{|c|}{ Full-matrix least-squares on $\mathrm{F}^{2}$} \\
\hline Data / restraints / parameters & \multicolumn{2}{|l|}{$3585 / 1 / 231$} \\
\hline Goodness-of-fit on $\mathrm{F}^{2}$ & \multicolumn{2}{|l|}{1.047} \\
\hline Final $R$ indices $[\mathrm{I}>2 \operatorname{sigma}(\mathrm{I})]$ & \multicolumn{2}{|c|}{$\mathrm{R} 1=0.0354, \mathrm{wR} 2=0.0878$} \\
\hline $\mathrm{R}$ indices (all data) & \multicolumn{2}{|c|}{$\mathrm{R} 1=0.0489, \mathrm{wR} 2=0.0963$} \\
\hline Absolute structure parameter & \multicolumn{2}{|l|}{$0.4(6)$} \\
\hline Extinction coefficient & \multicolumn{2}{|l|}{$0.037(6)$} \\
\hline Largest diff. peak and hole & \multicolumn{2}{|c|}{0.120 and -0.100 e..$\AA^{-3}$} \\
\hline
\end{tabular}

